\title{
Unifying structural priming effects on syntactic choices and timing of sentence generation
}

\author{
Katrien Segaert ${ }^{\mathrm{a}, \mathrm{b}, *}$, Linda Wheeldon ${ }^{\mathrm{a}}$, Peter Hagoort ${ }^{\mathrm{b}, \mathrm{c}}$ \\ a University of Birmingham, School of Psychology, UK \\ ${ }^{\mathrm{b}}$ Max Planck Institute for Psycholinguistics, Nijmegen, The Netherlands \\ ${ }^{\mathrm{c}}$ Radboud University Nijmegen, Donders Institute for Brain, Cognition and Behaviour, Centre for Cognitive Neuroimaging, Nijmegen, The Netherlands
}

\section{A R T I C L E I N F O}

\section{Article history:}

Received 29 August 2015

revision received 21 March 2016

Available online 26 April 2016

\section{Keywords:}

Structural priming

Syntactic choice

Production latency

Cumulativity

Verb repetition

Structure preference

\begin{abstract}
A B S T R A C T
We investigated whether structural priming of production latencies is sensitive to the same factors known to influence persistence of structural choices: structure preference, cumulativity and verb repetition. In two experiments, we found structural persistence only for passives (inverse preference effect) while priming effects on latencies were stronger for the actives (positive preference effect). We found structural persistence for passives to be influenced by immediate primes and long lasting cumulativity (all preceding primes) (Experiment 1 ), and to be boosted by verb repetition (Experiment 2 ). In latencies we found effects for actives were sensitive to long lasting cumulativity (Experiment 1). In Experiment 2, in latencies we found priming for actives overall, while for passives the priming effects emerged as the cumulative exposure increased but only when also aided by verb repetition. These findings are consistent with the Two-stage Competition model, an integrated model of structural priming effects for sentence choice and latency.
\end{abstract}

(c) 2016 Elsevier Inc. All rights reserved.

\section{Introduction}

Structural priming refers to the facilitation of syntactic processing that occurs when a syntactic structure is repeated across consecutive sentences. The most replicated finding in structural priming experiments is that speakers' syntactic choices are sensitive to priming: speakers choose to repeat, in the target utterance, (aspects of) the syntactic structure of the prime sentence, i.e. structural persistence. The phenomenon was experimentally demonstrated for the first time by Bock in 1986 (Bock, 1986). Following this seminal paper, structural persistence has been demonstrated experimentally for different syntactic structures in many different languages. For instance, speakers have a tendency to choose the same grammatical

\footnotetext{
* Corresponding author at: School of Psychology, University of Birmingham, Edgbaston, Birmingham B15 2TT, UK.

E-mail address: k.segaert@bham.ac.uk (K. Segaert).
}

voice (active versus passive voice) (e.g. Bock, 1986; Bock \& Griffin, 2000; Hartsuiker \& Kolk, 1998; Segaert, Menenti, Weber, \& Hagoort, 2011) or the same type of dative alternation (double object versus prepositional dative) (e.g. Bernolet \& Hartsuiker, 2010; Bock, 1986; Bock \& Griffin, 2000; Branigan, Pickering, \& Cleland, 1999; Hartsuiker \& Kolk, 1998; Kaschak \& Borreggine, 2008; Pickering \& Branigan, 1998; Segaert, Weber, CladderMicus, \& Hagoort, 2014). Models on structural priming assume that priming facilitates either the access to (Pickering \& Branigan, 1998), or the construction of syntactic structures (Chang, Dell, \& Bock, 2006; Chang, Dell, Bock, \& Griffin, 2000; Jaeger \& Snider, 2013), or a combination of both (Reitter, Keller, \& Moore, 2011). What these models have in common is a focus on explaining the speaker's choice in how his/her message is mapped on a syntactic structure during the process of syntactic encoding, while being less concerned with the time it takes to plan a syntactic structure for output. On the other hand latency data 
have been extensively used within the field of speech production to test other aspects of language production models, in particular models of incremental sentence planning (Kempen \& Hoenkamp, 1987; Levelt, 1989, 1992). Such planning models are less concerned with the speakers' choice of a global syntactic structure, and instead focus on the minimal pieces speakers have to plan before initiating the articulation of fluent sentences. Experimental research on the speed with which we can generate sentences has demonstrated that we can plan as little as the first word or phrase before we start to speak (e.g. Allum \& Wheeldon, 2007; Konopka, 2012; Martin, Crowther, Knight, Tamborello, \& Yang, 2010; Smith \& Wheeldon, 1999, 2001; Wheeldon, Ohlson, Ashby, \& Gator, 2013). So far, these two different bodies of research have developed largely in parallel, yet a complete model of sentence production would ideally explain the processes by which syntactic structures are chosen as well as the processes by which they are outputted.

One way of linking information on syntactic choice and information on the timing of sentence generation, are investigations of how structural priming impacts on sentence onset latencies. So far there are only a handful of experimental demonstrations of facilitatory effects of structural priming on the timing of sentence generation (Corley \& Scheepers, 2002; Segaert et al., 2011, 2014; Smith \& Wheeldon, 2001; Wheeldon \& Smith, 2003). Repeated syntactic structures are produced faster than novel syntactic structures, whether spoken or written. Similar to the priming effect on syntactic choices, the priming effect on production latencies illustrates that priming results in facilitated syntactic processing, with a reduction of processing resources needed to produce the target sentence.

Crucially however structural priming effects on latencies do not correspond in all details with those found on syntactic choices. Syntactic choice studies have established, three reliable characteristics of structural priming: (1) the inverse preference effect, i.e. priming of less preferred structures results in a larger persistence effect on syntactic choices, (2) cumulativity, i.e. multiple primes increase the effect of priming, and (3) the lexical boost, i.e. lexical repetition boosts the effect of priming. These key characteristics of structural priming have immensely impacted on the range of sentence production models that has been proposed to explain structural persistence effects (Chang, Janciauskas, \& Fitz, 2012; Chang et al., 2000, 2006; Jaeger \& Snider, 2013; Pickering \& Branigan, 1998; Reitter et al., 2011). To date, only the effect of structure preference has been tested on production latencies. In contrast to syntactic choices, latencies do not show an inverse preference effect, but consistently show a positive preference effect of structural priming, i.e. more preferred structures result in a larger priming effect on latencies (Segaert et al., 2011, 2014). Therefore in Segaert et al. (2011, 2014), we proposed a new unified model of structural encoding that reconciles the conflicting data from choice and latency paradigms: a Two-stage Competition model. According to the model, syntactic encoding consists of a selection stage during which one of the structural alternatives is selected, and a sequential planning stage during which production of the selected structure is prepared. Production latency is modelled as an additive effect of selection as well as planning time. The Two-stage Competition model reconciles the effects of structure preference on syntactic choice with the production latency data, and provides an explanation for inverse as well as positive preference effects.

However existing empirical evidence on the effects of structural priming in structure choices versus latencies currently begs the question whether structural priming effects are driven by separate or rather by shared mechanisms. Does the existing evidence of a positive preference effect on production latencies and an inverse preference effect on structure choices point toward fundamentally different mechanisms driving these effects? Or are we witnessing two sides of the same underlying mechanisms? If common mechanisms drive priming on production latencies and structure choices, then both types of priming effects should be sensitive to a range of similar variables. As mentioned above, syntactic choice measures of structural priming have yielded other robust effects, most noticeable the cumulative priming effect and the lexical boost effect. To date, these effects have not been tested in a latency paradigm. In this paper, we therefore test the model proposed in Segaert et al. $(2011,2014)$ by directly comparing the effects of the structure preference, cumulativity and lexical boost phenomena in syntactic choice and sentence onset latency data. We report two experiments designed to determine whether syntactic priming of latencies is sensitive to the same factors known to influence priming of choices. We investigate the active/passive voice alternation using a picture description paradigm, while simultaneously measuring production choices and latencies.

In what follows we first review the accumulated evidence for the inverse preference effect, cumulativity and lexical boost of priming on syntactic choices, as well as the syntactic encoding models proposed to explain them. We then describe the Two-stage Competition model originally proposed in Segaert et al. $(2011,2014)$ and its prediction regarding not only structure preference effects but also lexical boost and cumulativity effects.

\section{Factors influencing priming of choices and implications for syntactic encoding models}

A number of factors have been repeatedly identified to modulate priming of syntactic choices: the inverse preference effect, cumulativity and the lexical boost. The extensive research into these phenomena has been motivated by the promise of this research informing us about the characteristics that have to be taken into account by syntactic encoding models. Any factor that modulates structural persistence effects is evidently a variable that is taken into account by our syntactic processor.

Firstly, it is established that there is an inverse preference effect of priming on syntactic choices (Ferreira \& Bock, 2006). Priming effects on structure choices are larger for the less preferred syntactic alternative. In other words, there is an inverse relationship between the strength of the priming effect on syntactic choices on the one hand and the degree of preference or frequency of the structural 
alternative of the prime sentence on the other hand (Ferreira \& Bock, 2006; Scheepers, 2003). Passive prime sentences (the less preferred syntactic alternative) influence speakers more strongly to reuse this syntactic alternative than active prime sentences do (the more preferred syntactic alternative) (Bernolet, Hartsuiker, \& Pickering, 2009; Bock, 1986; Bock \& Loebell, 1990; Hartsuiker \& Kolk, 1998). In Dutch, the effects of priming on syntactic choices are larger for the double object dative than the prepositional object dative because the former is less frequent in Dutch (Bernolet \& Hartsuiker, 2010). In German on the other hand, the effects of priming on syntactic choices are larger for the prepositional object dative than the double object dative because in this language it is the prepositional object dative alternative that is generally less frequent (Segaert et al., 2014). Inverse preference effects have also been shown for optional that-complementizers (Ferreira, 2003), for high versus low relative clause attachment (Scheepers, 2003) and for frontal locative versus locative state sentences (Hartsuiker, Kolk, \& Huiskamp, 1999). Information on verb-specific preferences for syntactic alternatives has also been demonstrated to affect structural persistence (Bernolet \& Hartsuiker, 2010; Jaeger \& Snider, 2007, 2008, 2013; Reitter et al., 2011; Segaert et al., 2014). The less preferred a syntactic alternative is for a given verb, the stronger the structural persistence effect. In Dutch, the double object dative alternative is less preferred, but even more so for some verbs than others. For example the double object dative alternative is less preferred for 'doorgeven' (to pass) than for 'geven' (to give). Thus, priming the double object alternative with the verb 'doorgeven' (to pass) changes subsequent production choices more than priming this alternative with the verb 'geven' (to give) (Bernolet \& Hartsuiker, 2010). Theoretical proposals centering around implicit learning explain (verb-specific) inverse preference effects of syntactic priming on production choices in the following way: less frequent syntactic structures (for a given verb) are less expected so they are accompanied by a larger prediction error and by greater changes in implicit knowledge (Chang, Baumann, Pappert, \& Fitz, 2014; Chang et al., 2000, 2006; Jaeger \& Snider, 2013). Language users create expectations using all the information available to them. This includes prior knowledge about the relative frequency with which syntactic alternatives are produced, also for specific verbs (Jaeger \& Snider, 2013).

Secondly, there is convincing evidence that there is a cumulativity effect of priming on structure choices. Structural persistence effects have been shown to increase with the number of primes, in analyses of language corpora as well as in laboratory experiments. The likelihood of producing passive clauses and that-complementizers and relativizers was found to increase with the number of sentences in the same construction used previously in the corpus (Jaeger \& Snider, 2008). An experimental study by Kaschak, Loney, and Borreggine (2006) demonstrated that the likelihood of re-using double object and prepositional object dative constructions was determined by the number of times with which each constructional alternative occurred earlier within the experiment. These findings support the theoretical idea that structural persistence is a consequence of implicit learning (Bock \& Loebell, 1990; Chang et al., 2000, 2006). Every time a particular syntactic structure is processed, implicit learning takes place and the procedural knowledge that our syntactic encoder builds upon is updated. Chang et al. (2000, 2006) implemented error-based implicit learning as structural priming mechanism in a connectionist model. According to this model, language users predict upcoming words. A deviation between the expected and the observed serves as a signal to update procedural knowledge by adjusting weights in the connectionist network. These changes last over long time intervals. In fact, they stay in place until another sentence with the same or alternative structure is processed, which in turn further shapes the connection weights. An implicit learning model of structural priming accounts for how experiences with syntactic structures lead to long lasting influences on syntactic processing and for how experiences cumulate. In fact, syntactic priming experiments have demonstrated that increased exposure to a syntactic alternative changes the relative bias or relative preference for syntactic alternatives (for alternative word orders for auxiliary verb and past participle: Hartsuiker \& Westenberg, 2000; for datives: Kaschak, 2007). Moreover these changes in relative bias due to experience have been shown to last at least for a period of one week (Kaschak, Kutta, \& Schatschneider, 2011). This lends further support to an implicit leaning account of syntactic priming (Bock \& Loebell, 1990; Chang et al., 2000, 2006). Also Jaeger and Snider (2013) advocate the idea that syntactic priming is a consequence of implicit learning by the syntactic processor through expectation adaptation. They argue that language users adapt with the aim to minimize the experienced prediction error while they are processing subsequent syntactic structures. Through this mechanism, language users achieve efficient communication in a continuously changing environment.

Thirdly, numerous production studies have shown that there is a lexical boost of the structural persistence effect. When the lexical head of the structure (in most cases the main verb) as well as the syntactic structure are repeated between sentences, persistence effects are amplified compared to the effects due to structural priming alone (e.g. Branigan, Pickering, \& Cleland, 2000; Corley \& Scheepers, 2002; Hartsuiker, Bernolet, Schoonbaert, Speybroeck, \& Vanderelst, 2008; Pickering \& Branigan, 1998). The lexical boost phenomenon suggests a close connection between verbs and syntax, which is in accordance with lexicalist parsing models of syntax, in which syntactic processing is lexically guided (e.g. Bresnan, 2001; Jackendoff, 2002; Joshi \& Schabes, 1997; Macdonald, Pearlmutter, \& Seidenberg, 1994). Most notably, this phenomenon provided support for the theory proposed by Pickering and Branigan (1998), in which a residual activation mechanism drives the effects of syntactic priming. According to this theory, structural persistence is a consequence of residual activation of linked lexical and syntactic structure nodes, which persists for some time following the processing of the prime sentence (Cleland \& Pickering, 2003; Pickering \& Branigan, 1998). If the target is a transitive event that can be encoded with either an active or passive sentence, then residual activation left by a passive prime will bias the target towards encoding 
as a passive. Verb repetition across prime and target means that an extra portion of the prime's residual activation contributes during target processing, resulting in a stronger bias to use the primed structure.

\section{Factors influencing priming of latencies and the Two-stage} Competition model

Structural priming does not only influence subsequent structure choices; it also determines production latencies. Although the influence of priming on the latter aspect of sentence production is less well investigated (Corley \& Scheepers, 2002; Segaert et al., 2011, 2014; Smith \& Wheeldon, 2001; Wheeldon \& Smith, 2003), recent studies have demonstrated a positive structure preference effect: priming effects on production latencies are larger for more preferred syntactic alternatives (Segaert et al., 2011, 2014). Syntactic priming effects on production latencies are larger for actives than passives (Segaert et al., 2011) and are larger for double object datives than prepositional object datives in German (Segaert et al., 2014; the double object dative structure is generally more preferred in German). Similar to the inverse preference effect, the positive preference effect can also be determined by syntactic preferences which are specific to individual verbs. In Segaert et al. (2014) we demonstrated that the strength of dative priming in the production latencies was positively correlated with the degree to which the syntactic alternative was preferred for the verb used in the prime sentence. For example the double object dative alternative is more strongly preferred for the German verb 'leihen' (to lend) than for the verb 'liefern' (to deliver); the former thus resulted in stronger structural priming effects on latencies. In sum, the more preferred a syntactic alternative is for a given verb, the stronger the production latency benefit of producing this particular syntactic alternative.

As mentioned above, the existing theories of syntactic encoding are shaped to explain effects on syntactic choices rather than effects on production latencies. The residual activation theory proposed by Pickering and Branigan (1998) does not make specific predictions about latency effects, although other researchers have generated and tested latency predictions based on their own interpretation of this model (Corley \& Scheepers, 2002). The implicit learning theory of syntactic priming is a theory about structure selection and in the current implementation of the Chang et al. model $(2000,2006,2014)$ there is no standard way of deriving timing predictions. Also the model proposed by Jaeger and Snider (2013) currently does not incorporate a link function which would allow predictions about latencies. In sum, in their current form none of the established theories is intended to specify predictions about structural priming effects on production latencies. Moreover, the stable positive preference effect for production latencies would be paradoxical for any straightforward extension of these models, which would predict parallel effects of preference on syntactic choices and production latencies. Therefore in Segaert et al. (2011, 2014), we proposed an account of structural priming aimed at explaining the production latency effects observed so far.
The Two-stage Competition model (Segaert et al., 2011, 2014) consists of a selection stage and a planning stage (see also Fig. 1 for a schematic overview of the mechanisms in the selection stage). Sentence production begins with the construction of a message; minimally a thematic structure

(A) Baseline

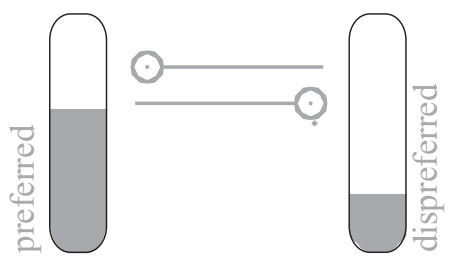

(B) Priming the more preferred alternative

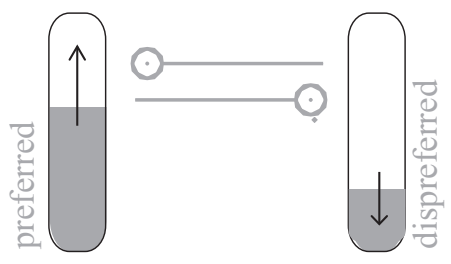

(C) Priming the less preferred alternative

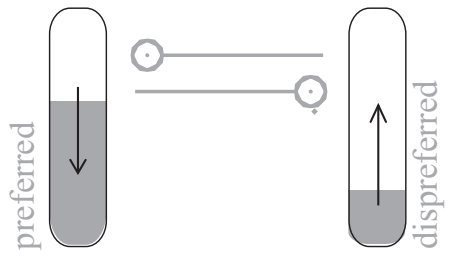

Fig. 1. Schematic overview of the mechanisms in the selection stage of the Two-stage Competition model. Sentence production begins with the construction of a message; minimally a thematic structure detailing who does what to whom. Message encoding is followed by a selection stage in which a speaker selects a mapping of the thematic roles to one structural alternative (e.g. actives vs. passives); then follows the planning stage (not shown in the figure) during which production is planned incrementally. While structure choice is determined exclusively during the selection stage, production latency is an additive effect of the time taken in both the selection and planning stages. Between the two structural alternatives there is competition: each node inhibits the other in proportion to its own activation level; the selection time is determined by the amount of time it takes to resolve competition. The selection time thus changes due to priming and the changes differ for preferred and dispreferred structures. Planning time always decreases as a result of priming. Displayed are for the selection stage the (changes in) average activation levels for the preferred (left) and dispreferred (right) structural alternative in three situations. (A) The baseline (unprimed) situation. The average base-level activation of each node is positively related to the frequency of occurrence of the corresponding structural alternative. As a consequence of structural priming, the average activation levels of the nodes change; (B) priming the more preferred alternative results in (i) an increased difference in activation levels between the nodes, (ii) a decreased selection time and (iii) a decreased planning time; (C) priming the less preferred alternative results in (i) a decreased difference in activation levels between the nodes, (ii) an increased selection time and (iii) a decreased planning time. The selection time and the planning time contribute to the production latency as additive effects and thus only for preferred structures priming results in speeded response latencies. Note that for actives, which have a highly asymmetrical structure preference relationship with their alternative, priming would not likely affect selection since active are already at a ceiling level. 
detailing who does what to whom (e.g. Levelt, 1989; Ferreira \& Slevc, 2007). Message encoding is followed by the selection stage, during which a speaker selects a mapping of the thematic structure to one grammatical structural alternative (e.g. an active or passive) in order to express the message linguistically (e.g. Bock \& Levelt, 1994). Next follows the planning stage during which the utterance to be produced is constructed. We assume a structurally driven planning process, in which global aspects of the utterance are constructed followed by the incremental generation of syntactic phrases to which lexical items are assigned (e.g. Allum \& Wheeldon, 2007, 2009; Griffin \& Bock, 2000; Konopka \& Kuchinsky, 2015; Konopka \& Meyer, 2014; Kuchinsky, Bock, \& Irwin, 2011; Smith \& Wheeldon, 1999; Wheeldon et al., 2013). The global syntactic structure built in the planning stage determines the order of the argument phrases and thus the hierarchical syntactic frame. Local planning involves the incremental assignment of lexical content to local phrases prior to production. In sum, for the utterances elicited in our task, we thus assume that prior to sentence onset, message planning and structure selection is completed along with the planning of the global syntactic hierarchy and the construction of the sentence initial phrase (Smith \& Wheeldon, 1999; but see Brown-Schmidt \& Konopka, 2008, 2015).

While structure choice is determined exclusively during the selection stage, production latency is an additive effect of the time taken in both the selection and planning stages. The priming effects of structure choice will thus be a reflection of changes due to priming within the selection stage of the model, while the priming effects on production latencies will thus be a reflection of changes due to priming in both stages of the model.

Competition models of syntactic encoding propose that alternative syntactic structures are in active competition to be selected. These types of models are often implemented in an interactive activation architecture (McClelland \& Rumelhart, 1981) in which activation spreads through the model through excitatory and inhibitory connections. The latter connect representations of alternative syntactic structures (e.g. actives and passives); this implements the competition aspect of the model. The time needed to reach a threshold for activation and select one of the alternatives is an indication of how difficult it is to make the selection. The model we are proposing in a Two-stage Competition model in which the production frequency or preference of each syntactic alternative is a very important contributor. In our model, structural alternatives are represented by competing nodes (i.e. connected by inhibitory connections - see below). The base-level activation of each node is positively related with the frequency of occurrence of the structural alternative it represents. This is established through an implicit learning mechanism, updating information with each exposure to a syntactic alternative (similar to Jaeger \& Snider, 2013). Cumulative exposure to a constructional alternative will ensure that the base-level activation of a node is updated.

For any competition model in which production preferences contribute to the selection process, a critical issue is how the less preferred structural alternative is ever selected in a baseline or unprimed situation, especially when there is a highly asymmetrical preference relation- ship with their structural alternative (as is the case for the passive voice in many languages, like English and Dutch). Of course, in natural language, the discourse can strongly bias a speaker towards using the passive voice, e.g., What happened to the ball? - It was kicked by Susan. Moreover, in some experimental situations, attentional cues to protagonists have been shown to affect order of mention (Gleitman, January, Nappa, \& Trueswell, 2007; Kuchinsky \& Bock, 2010, see Bock \& Ferreira, 2014, for a review of lexical factors in sentence production). A low level of unprimed passive structures is usually observed in experimental situations in the absence of such overt discourse or cuing factors e.g., Segaert et al. (2011) observed $6-8 \%$ occurrence of unprimed passives in Dutch.

In our model, for unprimed sentences, the structure choice in the selection stage is predominantly determined by the average base-level activation of the competing nodes representing the competing alternatives. On average, for structural nodes with high base-level activation, the amount of activation that needs to be sent to activate the node is lower than the amount of activation that needs to be sent to a node with low base-level activation. Therefore on average, structure choice will be in favor of the former. However, for a number of reasons the passive voice may occasionally become more highly activated than the active. For instance, the speaker may on occasion fixate strongly on the patient in the picture and choose it for first mention. Such factors will cause fluctuations around current activation levels and can be thought of as noise in the system (e.g. Dell, 1986). This noise will play a role in all experimental conditions. Critically however, in the unprimed condition such factors will result in passives rarely but swiftly winning the competition with the active alternative. In other words, there is a small chance in the unprimed condition that noise will favor the passive and, furthermore, that when this happens the noise is sufficiently powerful that the passive is rapidly selected. In effect, we are assuming that unprimed passives, when they happen, are triggered by some powerful factor, possibly related to focus of attention on the picture or the message.

For primed sentences, residual activation will influence the structure choices. The idea of residual activation is inspired by Pickering and Branigan (1998), however unlike Pickering and Branigan (1998) we do not predict the same amount of residual activation for each primed structural alternative. In our account, more activation needs to be sent to activate a node with low base-level activation, therefore more residual activation is present for the node representing the less preferred structure during the production of subsequent target sentences. When a less frequent structure is primed, the structure choices are thus more likely to be affected than when a more frequent structure is primed (i.e. inverse preference effect). Similar to Pickering and Branigan (1998), our model predicts a lexical boost of priming effects on structure choices: nodes representing syntactic alternatives are linked to specific verbs (Segaert et al., 2014), therefore verb repetition across prime and target means that additional residual activation is present during target processing, with a stronger bias towards the primed alternative as a result. As mentioned before, cumulative priming results in changed base-level 
activations which in turn affects structure choices during target sentences.

Now that we have explained the main processing mechanisms pertaining to the structure choice component of syntactic priming, let us turn to the production latency component of syntactic priming. The crucial mechanism in our model is competition in the selection stage between structural alternatives. More specifically, lateral inhibition (negative activation) is sent between competing alternatives. Inhibition decreases the amount of activation of a competitor node; each node inhibits the competitor in proportion to its own activation level. In other words, the amount of inhibition transmitted is a positive function of the current activation level. Lateral inhibition is an assumption incorporated in several models of word selection in comprehension and production (e.g. Berg \& Schade, 1992; Dell, Burger, \& Svec, 1997; McClelland \& Elman, 1986; Roelofs, 1992). The transmission of inhibition thus enhances differences in activation levels between nodes. Competition in the selection stage is only resolved when the difference in activation levels between competitors has reached a threshold for activation. In other words, the structure choice selection time is determined by the time needed to solve competition between competitor nodes. Selection time decreases with an increasing difference in average activation levels between competitors at the moment competition starts: the higher the current activation of a node, the more inhibition it transmits to the competitor; the lower the latter's activation, the less inhibition it can retort, etc. Production latencies are the result of the additive effect of the structure choice selection time and the production planning time.

Firstly, we will discuss how priming influences the selection time in the model. Following a prime with a more preferred structure, the difference in average activation levels of this structure and its competitor increases during the target sentence due to residual activation. In this case, when priming increases the difference in average activation levels between competitors (compared to the difference in base-level activation of the competitors), less time is needed to resolve competition and thus the selection time decreases. On the other hand when a less preferred structure is primed, priming decreases the difference in activation levels between competitors compared to the base-level situation, thus priming increases the competition time in the selection stage. In the case of passives: a passive prime would result in residual activation, making the passive a more likely contender in the competition process with the active. Therefore on a subset of subsequent targets, the passive voice can be selected following a long competition process of inhibitory activation exchange with the active voice alternative. Counterintuitively therefore, the selection time of these primed passives will be slower than that of the rare unprimed passives.

Second, we discuss how in the model priming influences the planning time. We assume that priming reduces the planning time in line with Levelt and Kelter (1982), regardless of whether the syntactic structure is more or less preferred. Once the speaker has chosen a structure, the structure has to be built. We assume that when constructing a sentence for output, the planning prior to sentence initiation involves the construction of some global and some local aspects of the syntactic structure (Smith \& Wheeldon, 1999). We assume both aspects to be facilitated when primed. The global planning involves the generation of the hierarchical structure that determines the relationships between grammatical phrases and their order of output, irrespective of lexical content. The local planning involves the incremental construction of grammatical phrases or the retrieval of syntactic templates (Hagoort, 2005; Vosse \& Kempen, 2000). Prior to speech onset we assume that local planning is completed for the sentence initial phrase, with the following phrases/ syntactic templates constructed/retrieved incrementally (e.g. Allum \& Wheeldon, 2007, 2009; Smith \& Wheeldon, 1999; Wheeldon et al., 2013). As stated above, the selection time and planning time contribute to the production latency as additive effects. For more preferred structures, priming decreases the selection time and decreases the planning time, which results in a production speed-up. For less preferred structures, planning time also decreases, but this is cancelled out by an increase in selection time, eliminating the priming benefit in the production latencies (or in some cases even resulting in an increase in the latencies for repeated structures). With these processing mechanisms, the Two-stage Competition model thus predicts a positive preference effect of structural priming effects on latencies.

The Two-stage Competition model furthermore predicts that verb repetition and cumulativity will modulate choice as well as latency priming. The production latency benefit of repeating a syntactic structure is predicted to increase when there is verb repetition due to changes in the selection stage. Verb repetition can magnify the effect of priming on the selection time, for both syntactic alternatives, because nodes representing syntactic alternatives are linked to specific verbs. For actives, the repeated verb would magnify the effect of priming on the selection time, speeding it up further, as it would make the active even more distant from the passive. For passives, verb repetition would likely bring the primed passive even closer to active, thus further slowing the selection time. Verb repetition would not necessarily be expected to affect planning time though, since detailed production planning is incremental and SVO (Subject-Verb-Object) sentences are likely to be initiated prior to verb selection (e.g., Martin et al., 2010; Schriefers, Teruel, \& Meinshausen, 1998). Lexical repetition of the verb would also not be expected to influence global planning of the structure of the utterance, in which lexical items are still to be inserted. Because production latency is determined by selection time as well as planning time, any influence of verb repetition on latencies is predicted to be less pronounced than on choices, which are solely determined by the selection stage. (Note that this effect might not be observed for actives, which are a special case of the preferred syntactic alternatives, because of the strongly asymmetrical relationship with their alternative, but is predicted for preferred alternatives with a less asymmetrical preference relationship, e.g. datives.)

The Two-stage Competition model predicts latency benefits to increase when there is cumulativity due to changes in both the selection and the planning stage. 
Cumulative priming results in changed base-level activations which in turn affects competition between syntactic alternatives and the selection time. For less preferred structures, cumulative exposure can boost the base-level activation of the structure to such a level that when preceded by an immediate prime, the less preferred structure now has an activation level close to or even higher than that of the preferred structure. For more preferred structures, cumulative exposure can also boost the base-level activation (although note that for the special case of actives, the influence of cumulativity on the selection stage is unlikely because the selection of actives is already at ceiling). Cumulativity is also expected to affect the planning time, for both syntactic alternatives. In our model, we assume global planning of the syntactic structure of the utterance and we expect cumulativity to facilitate this process (note that we do not manipulate local planning in this study as active, passive and intransitive sentences have similar sentence initial phrases). In sum, the priming effect on latencies is predicted to be modulated by cumulativity due to changes in both the selection and planning stage. Cumulativity and verb repetition can also jointly increase the latency benefits of repeating syntactic structures: cumulative exposure to the less preferred structure could bring the average activation level close to that of the preferred structure, verb repetition in addition to this could result in an average activation level of the less preferred structure that is even slightly higher than that of the preferred structure. Thus, in a situation of cumulative exposure to passives, verb repetition could lead to the primed passive having a higher activation level than the active, therefore resulting in speeded selection times and by consequence also speeded response latencies.

\section{The present study}

The aim of the two experiments reported below is to expand the data on structural priming to include the effects on production latencies of cumulativity and verb repetition, as well as the relationship between the latency effects and structural choice effects. To examine the structural priming effects on syntactic choices, we will measure syntactic choices in priming conditions as well as in a baseline condition. Without inclusion of a baseline one can assess whether a priming effect occurs by comparing the effects of two priming alternatives (Bock, 1986), but the inclusion of and comparison to a baseline condition is necessary to examine whether only one of the primes affects the syntactic choices, or both primes affect the syntactic choices, and to what extent. Structural priming effects on production latencies are examined by comparing the production latencies on target sentences for which the speaker chooses to repeat the structure (i.e. structural persistence), to latencies on target sentences for which the speaker did not repeat the structure (i.e. no structural persistence). In doing this, we follow the same approach as the only other researchers who have examined categorical as well as latency evidence of structural priming simultaneously (Corley \& Scheepers, 2002). But more importantly, with this approach one can examine the relationship between effects of structural priming on both dependent measures: what is the effect on production latencies when the speaker chooses to repeat versus not repeat the syntactic structure of the prime. Both reported experiments test the structural priming of actives as well as passives (which are high frequent versus low frequent structures respectively) in comparison to baseline, therefore both experiments assess the effect of structure preference on the amount of priming observed in both dependent measures. Moreover in Experiment 1 we test for a cumulative effect of structural priming on both syntactic choices and latencies. Additionally, In Experiment 2 we test whether the structural priming effects on choices and latencies are boosted by verb repetition. These experiments therefore test whether the paradoxical influence of structure preference on the effects of priming on syntactic choices versus production latencies generalizes to different priming conditions, as well as allow us to evaluate in how far the Two-stage Competition model of structural encoding can explain the observed patterns of modulations of cumulativity and verb repetition on the effects of priming on both dependent measures.

\section{Experiment 1: The influence of structure preference and cumulativity on the effects of priming on syntactic choices and production latencies}

Our first experiment was designed to investigate the influence of structure preference and cumulativity on the effects of priming on both syntactic choices and latencies. We primed the production of both active (high frequency) and passive (low frequency) transitive sentences in order to test the influence of structure preference on the effects of priming on syntactic choices and latencies. We tested the immediate effect of cumulativity by measuring the effect of the number of directly preceding primes (1 versus 3 ) on choices and latencies. We also investigated the longer lasting effect of cumulativity by measuring the cumulative effect of all preceding active vs. passive target productions over the duration of the experiment. This is measured as the effect on choices and latencies, of the proportion of passive target productions out of the total active and passive productions in the experiment so far (hereafter: Cumulative Passive Proportion) (following a similar method to Jaeger and Snider (2013) and Heyselaar, Hagoort, and Segaert (2015)). Syntactic priming has previously been shown to be affected by both prior and recent experience, in corpus analyses as well as experimental paradigms, which is in accordance with an expectation adaptation account of syntactic priming (Jaeger \& Snider, 2013). Prior experience constitutes our experiences that passives are produced infrequently (about $8 \%$ in Dutch: Cornelis, 1996). Cumulative Passive Proportion is a measure of more recent experience with passives.

\section{Materials and methods of Experiment 1}

\section{Participants}

Forty-five native Dutch speakers (21 male/24 female, mean age of 22 years with $S D$ 3.1) gave written informed 
consent prior to the experiment and were compensated for their participation.

\section{Materials}

In our experiment the participants were presented with pictures and were asked to describe these. The prime and target pictures depicted two people performing a transitive action (e.g. kissing, serving or feeding). The pictures depicted a total of 36 different events (Table 1 in Appendix), all eliciting transitive sentence descriptions. Each event was enacted by four different couples; either two adult or two children, with always one female and one male. All couples were photographed twice for each event: once with the female as the agent and once with the male as the agent. We furthermore made one copy of each picture with the agent on the left and one with the agent on the right. Lastly, for each of these pictures three versions were created: two color-coded versions to serve as prime pictures (one eliciting an active sentence and one eliciting a passive sentence - see task description) and one grayscale version to serve as the target picture.

Filler pictures either elicited intransitive sentence descriptions depicting events such as running, singing, bowing with one actor (in grayscale, green or red), or elicited locative sentence descriptions showing events such as

Table 1

List of the transitive actions which are depicted in the stimuli.

\begin{tabular}{ll}
\hline Verbs in Dutch infinitive & English translation \\
\hline aankleden & to dress \\
achtervolgen & to follow \\
afdrogen & to dry \\
bangmaken & to scare \\
bedienen & to serve \\
bedreigen & to threaten \\
betalen & to pay \\
begroeten & to greet \\
duwen & to push \\
fotograferen & to photograph \\
interviewen & to interview \\
helpen & to help \\
knuffelen & to embrace \\
masseren & to massage \\
meetrekken & to pull \\
meten & to measure \\
optillen & to lift \\
overeindhelpen & to help getting up \\
omtrekken & to pull down \\
natmaken & to wet \\
neerschieten & to shoot down \\
schoppen & to kick \\
pesten & to tease \\
slaan & to hit \\
slepen & to drag \\
stoppen & to stop \\
tekenen & to draw \\
naroepen & to call to \\
troosten & to comfort \\
uitzwaaien & to wave goodbye \\
vastbinden & to tie \\
verzorgen & to look after \\
vinden & to find \\
voeren & to feed \\
wegsturen & to send away \\
wurgen & to strangle \\
&
\end{tabular}

standing, sitting, lying with either two objects or one actor and one object (either grayscale or color-coded to elicit a locative state or a frontal locative). Intransitive ('The man sings') and locative sentences ('The bottle stands on the table'; 'On the table stands a bottle') serves as filler sentences as well as prime sentences for target descriptions in the baseline condition (see below).

\section{Task and design}

The task and design of this experiment are illustrated in Fig. 2. Participants were instructed to describe pictures with one sentence, naming the green actor before the red actor if two actors were depicted in color. If the actors were not depicted in color then participants did not have to pay attention to the order of mentioning the two actors and could therefore produce either an active or a passive sentence.

Each trial consisted of one or more prime sentences followed by a target sentence. Target sentences were transitive sentences elicited by a grayscale target (example in 2 of Fig. 2). There were two types of prime sentences: (a) baseline prime sentences and (b) transitive prime sentences. During the baseline trials (a) an intransitive or locative prime sentence was followed by a transitive target sentence. These baseline trials allowed us to measure the baseline frequency of producing active and passive transitives when not primed by a transitive sentence. The transitive prime sentences (b) were elicited by pictures in which actors were color-coded for the order of precedence in the sentence, allowing us to manipulate the syntactic structure participants would produce (examples in 1b of Fig. 2). On transitive priming trials we measured the syntactic priming effect in four conditions (Fig. 2), resulting from a manipulation of the syntactic structure of the prime sentence (active versus passive voice), fully crossed with a manipulation of the number of prime sentences ( 1 versus 3 primes). The actors in prime and target pictures were always different (i.e. children followed by adults or vice versa) so participants were not repeating actors names between primes and targets. In Experiment 1 the verb was never repeated between primes and targets.

Each experimental list contained 20 targets in each of the 4 transitive priming conditions and 40 targets in the baseline condition. We randomly choose, from the picture set described above, the target pictures to appear in the ' 1 prime' and the target pictures to appear in the ' 3 primes' condition; from this we generated 3 counterbalanced lists so that across each triplet of experimental lists the same target picture occurred once with one or three baseline primes, once with one or three transitive primes in the active version and once with the same one or three transitive primes but in the passive version (and we repeated this procedure starting from a different random picture subset 15 times, in order to create 45 experimental lists). Within each experimental list, this resulted in 120 transitive descriptions on target pictures, 160 transitive descriptions on prime pictures and 80 intransitive or locative descriptions leading up to a target in the baseline condition.

Intransitive and locative sentences did not only serve as prime sentences in the baseline condition but also served 
1a Baseline prime sentence

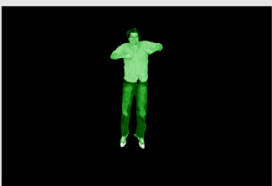

The man jumps

\section{1b Transitive prime sentence}

One prime sentence
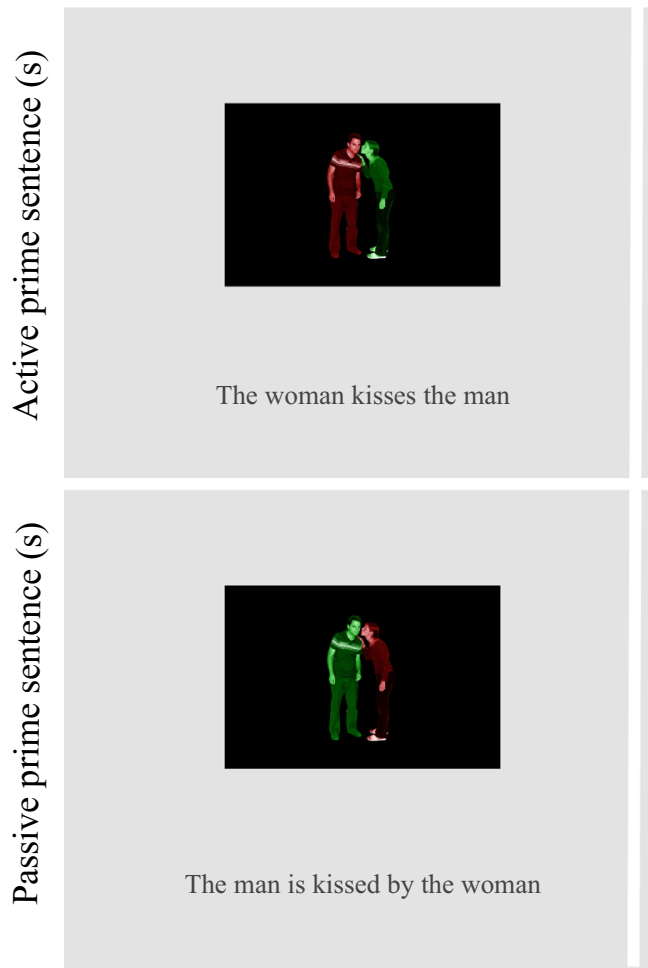

\section{Target sentence}

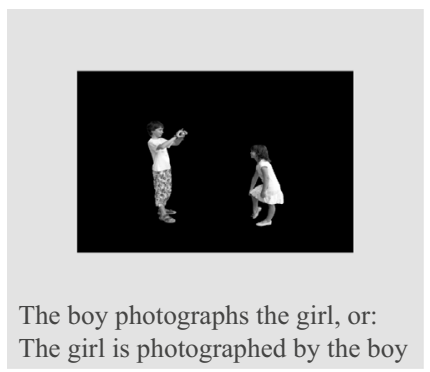

The boy photographs the girl, or:

The girl is photographed by the boy
Three prime sentences

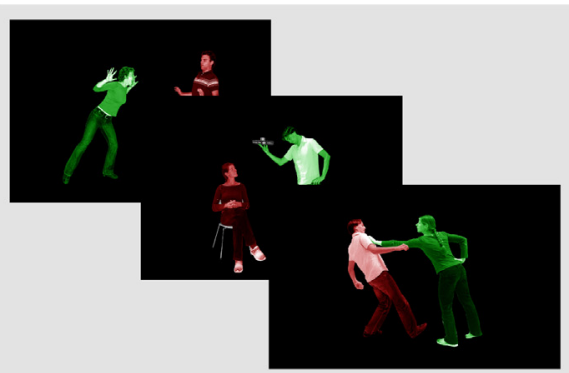

The woman scares the man

The man serves the woman

The woman pushes the man

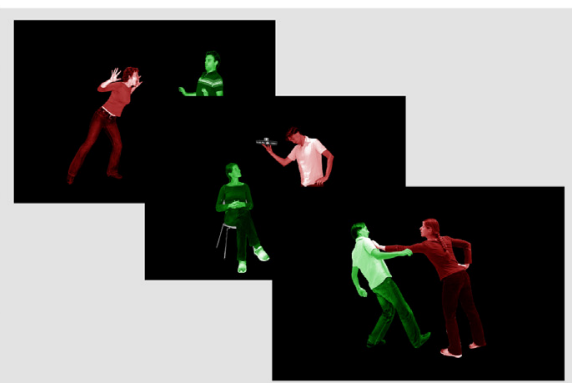

The man is scared by the woman

The woman is served by the man

The man is pushed by the woman

Fig. 2. Design Experiment 1. Baseline prime sentences (1a) were elicited by pictures in which the actors were colored or grayscale, eliciting an intransitive or locative sentence. Transitive prime sentences (1b) were elicited by pictures in which actors were color-coded for the order of precedence in the sentence, thus eliciting a sentence in active or passive voice. Target sentences (1c) were elicited by grayscale pictures such that we could measure syntactic choice as well as production latency. We measured structural priming effects in the baseline condition and four transitive priming conditions, the latter resulting from a manipulation of the structure of the prime sentence (active versus passive voice) fully crossed with a manipulation of the number of prime sentences (1 versus 3 primes). (For interpretation of the references to color in this figure legend, the reader is referred to the web version of this article.) 


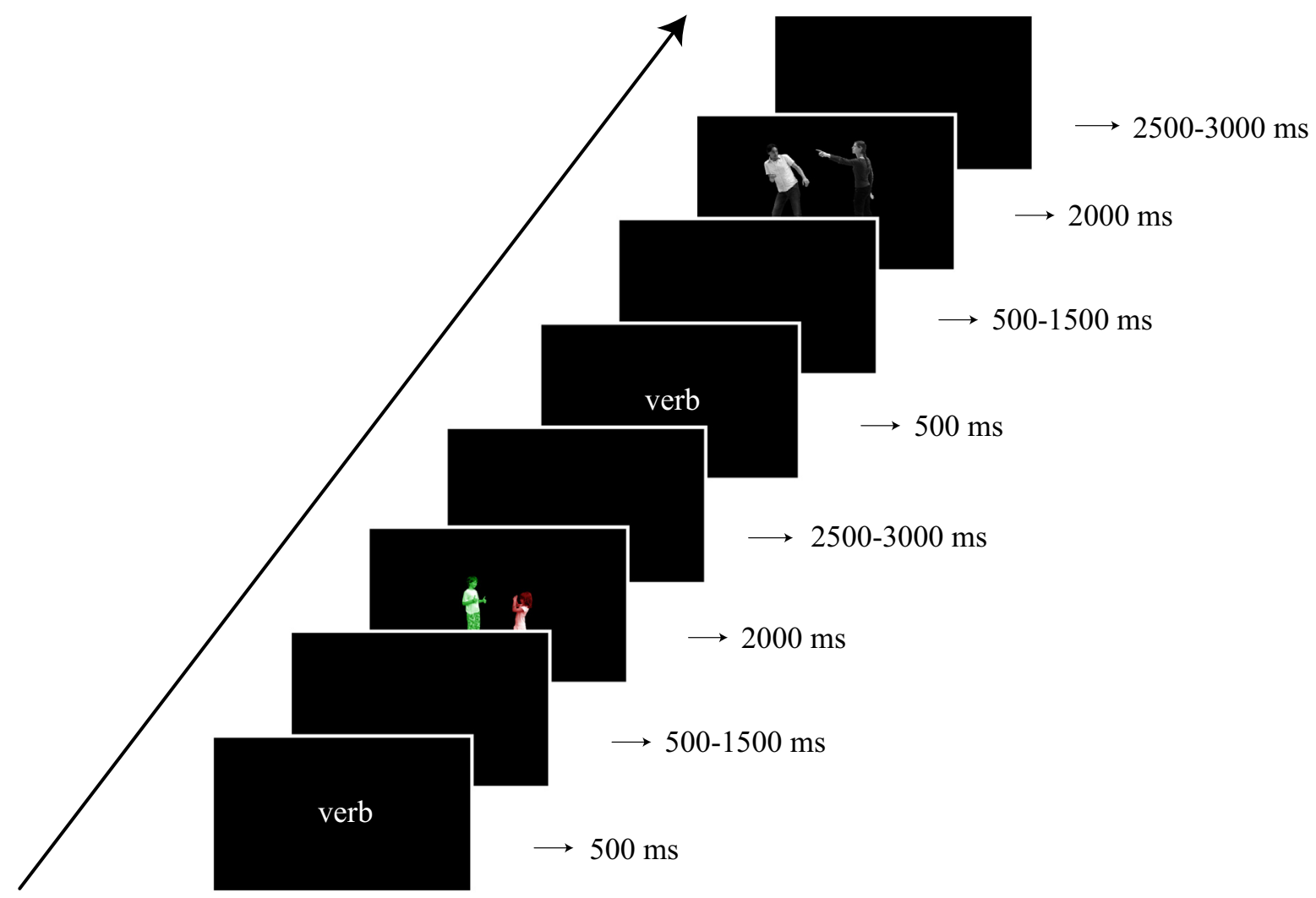

Fig. 3. Procedure. Sequence of events and the timing of each event during a trial.

as additional filler sentences (another 140 sentences added). In total there were thus 500 sentences in the experiment. Over the whole experimental list only $56 \%$ of the items ( 280 out of the total of 500 sentences) elicited transitive sentences.

\section{Experimental procedure and scoring criteria}

Participants received ten practice trials at the beginning of the experimental session. The actual experiment lasted $60 \mathrm{~min}$. Fig. 3 illustrates the sequence of events on each trial. Participants' responses were recorded and a voice key measured sentence onset latency relative to the onset of picture presentation.

Responses were manually coded as active (e.g. "The man kisses the woman", in Dutch: "The man kust de vrouw") or passive (e.g. "The woman is kissed by the man", in Dutch: "De vrouw wordt gekust door de man"). Responses were considered for analysis only if, during prime and target trial, (1) the two actors as well as the verb were named the correctly, and (2) the description was complete (e.g. "The woman is kissed by the man" versus "The woman is kissed"), and (3) no necessary additional information was included in the description. The scoring criteria and decision to score as active versus passive were thus unambiguous. Coding was done by an independent coder who was unaware of the purpose of the experiment. Debriefing showed that participants were unaware of the purpose of the experiment.

\section{Data analysis procedure}

We analyzed the data using mixed-effects logit and linear models (Barr, Levy, Scheepers, \& Tily, 2013; Jaeger, 2008; Pinheiro \& Bates, 2000) in R (R Development Core Team, 2009). During the process of model comparison, we would start from a model including all factors motivated by the experimental design and a fully specified random effect structure. We then simplified the model using model comparison for fixed effects. When a model with a fully specified random effects structure did not converge, we removed random slopes according to the following strategy: we removed the random slopes for items before removing any random slopes for subjects (since in researcher-designed experiments the variance for items is usually smaller than for subjects), and we removed interaction terms before main effects, until convergence was reached. Main models are summarized in tables; coefficient estimates are included in the text only when a full summary is not included in the tables.

\section{Results of Experiment 1}

\section{Syntactic choices}

We excluded 7\% (361 out of 5400) of the responses on baseline and transitive priming trials (criteria are described under 'Experimental procedure and scoring criteria'). Fig. 4 and Table 2 summarize the syntactic choice data. The random effects structure for the model includes 
A

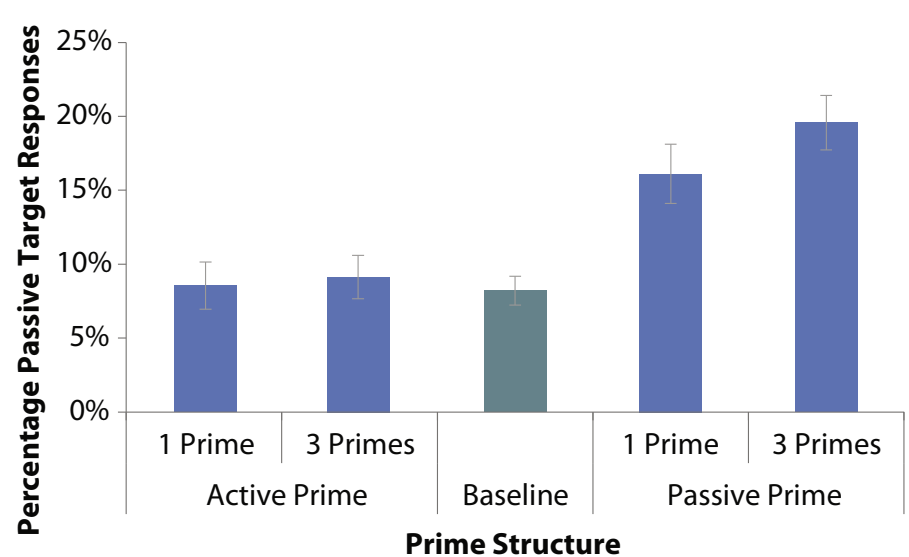

B

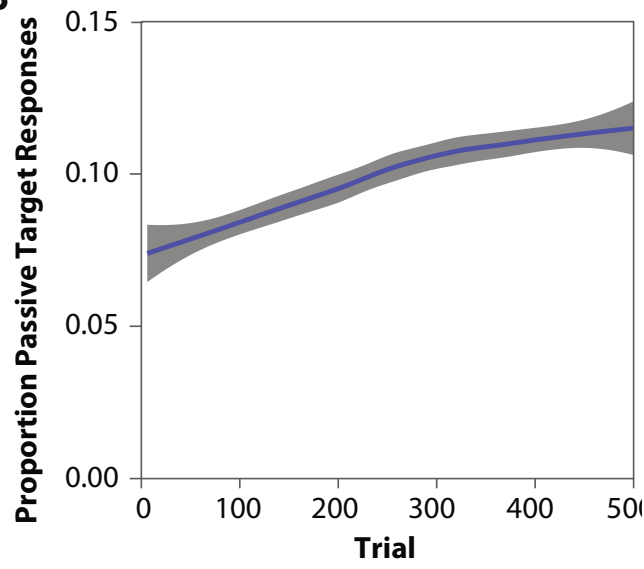

Fig. 4. Syntactic choice results of Experiment 1. (A) Replicating the inverse preference effect, we found that syntactic choices were not affected by active primes, but were affected by passive primes compared to baseline. There was an immediate effect of cumulativity on structural persistence: choices were influenced more by 3 passive primes than 1. (B) The proportion of passive target responses is illustrated to increase over trials within the experiment. We found that the higher the Cumulative Passive Proportion, the more passives were produced during the target sentence. This indicates there was a long term effect of cumulativity as well.

Table 2

Summary of fixed effects in the mixed logit model for the syntactic choices in Experiment 1.

\begin{tabular}{lclrl}
\hline Predictor & Coefficient & $S E$ & Wald Z & $p$ \\
\hline Intercept (Baseline) & -2.93 & 0.16 & -17.76 & $<.001^{* * *}$ \\
1 active prime & -0.24 & 0.23 & -1.02 & $>.3$ \\
3 active primes & 0.10 & 0.17 & 0.58 & $>.5$ \\
1 passive prime & 0.74 & 0.15 & 4.98 & $<.001^{* * *}$ \\
3 passive primes & 1.21 & 0.15 & 8.12 & $<.001^{* * *}$ \\
Cumulative Passive & 2.03 & 0.69 & 2.93 & $<.004^{* *}$ \\
$\quad$ Proportion & & & & \\
\hline
\end{tabular}

Note: $N=5039$, log-likelihood $=-1609$.

${ }^{* * *}<.001 ;{ }^{* *}<.01$.

a random intercept for subjects and items and a random slope for Condition for subjects (this is the maximal random effect structure for which convergence is reached).

To assess whether the structural persistence effect is greater for passives than actives (i.e. the inverse preference effect), one must compare the syntactic choices in priming conditions to the syntactic choices in a baseline condition. In order to statistically assess these crucial comparisons, a predictor 'Condition' with five levels was added to the model using treatment coding. In Table 2, the baseline condition was included in the intercept and contrasted with the four conditions that result from fully crossing 'Prime structure' and ' 1 vs. 3 Primes'. To assess the other statistical differences between each of the five conditions (e.g. 3 Passive Primes vs. 1 Passive Prime), we refitted the same model but with a different condition than the baseline as reference level (e.g. reference: 3 Passive Primes). To examine cumulativity we did not only include the predictor ' 1 vs. 3 Primes', which only assesses the immediate effect of cumulativity, but also of a predictor 'Cumulative Passive Proportion', which was centered on the mean. The Cumulative Passive Proportion variable lists for each target trial a value that reflects the proportion of passives out of the total active and passive target productions in the experiment so far (excluding the current trial). Target responses were coded as 0 for actives and 1 for passives.

The negative estimate for the intercept thus indicates that in the baseline condition actives were more frequent than passives. Replicating the inverse preference effect, we found that syntactic choices were not affected by active primes compared to baseline ( 1 prime: $p>.3,3$ primes: $p>.5$ ), but were affected by passive primes compared to baseline ( 1 prime: $p<.001,3$ primes: $p<.001$ ). The structural persistence effect was also found to be cumulative. Firstly, there were more passive productions following 3 passive primes than $1(\beta=0.48, p<.006)$. Secondly, the higher the Cumulative Passive Proportion in the experiment so far, the more passives were produced during the target sentence $(p<.004)$, suggesting a long term effect of cumulativity. There were not more active productions following 3 active primes than 1 ( $\beta=.32, p>.16)$. A model including an interaction between Cumulative Passive Proportion and Condition was not a better model fit than a model excluding this interaction $\left(\chi_{4}^{2}=4.59, p>.33\right)$.

\section{Production latencies}

For the analyses of the production latencies we created a post hoc variable "Syntactic repetition" with the levels No syntactic repetition and Syntactic repetition. This variable captures the relationship between the prime structure and the structure of the participant's target response. In other words, when this variable shows to be a significant predictor of the latencies, it demonstrates that there is a relationship (although not necessarily of a causal nature, since the variable is created post hoc) between the effects of structural priming on the syntactic choices and the latencies.

Of the correct responses on the priming trials, we excluded 12\% (399 out of 3323) because they contained sounds triggering the voice key before speech onset (e.g. "euhm", "mhm") or because they were two standard deviations below or above the mean calculated per subject and per condition (Ratcliff, 1993). We used deviation 


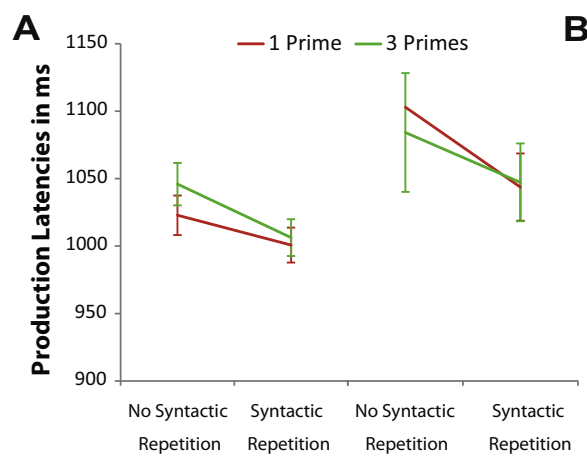

Actives

Passives
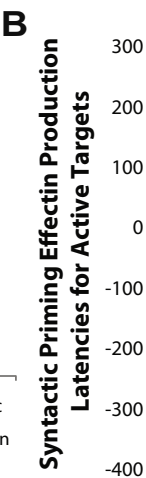

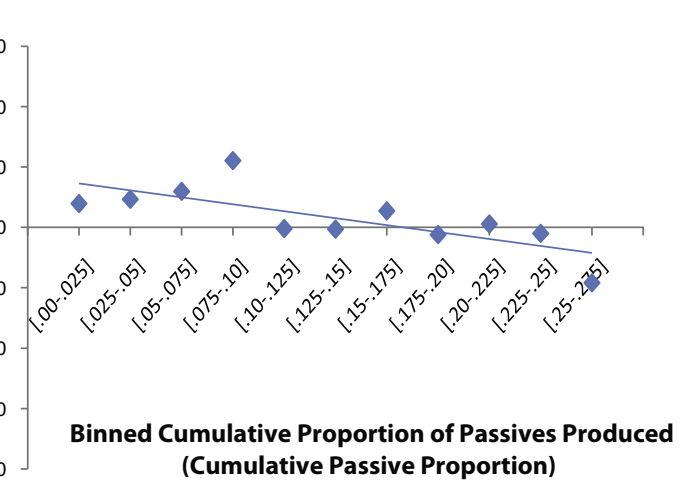

Fig. 5. Production latency results of Experiment 1. (A) The syntactic repetition effects are plotted for the 1 Prime and 3 Primes condition separately. Syntactic repetition significantly speeded up latencies for active structure choices, but not for passive structure choices. Although visually it looks like there is a production latency benefit for passives, the effect is too variable to reach significance (for comparison, see also Fig. 8A which also depicts a nonsignificant difference). Our findings are in line with the positive preference in latencies previously reported in the literature. (B) The syntactic repetition effect for actives interacted with Cumulative Passive Proportion: the higher the cumulative proportion of passives (and thus: the smaller the cumulative proportion of actives), the smaller the priming effect for actives. This indicates there is a cumulative effect of priming for actives in the production latencies. (In the figure, cumulative Passive Proportion is binned for visualization purposes. Analyses were performed using a continuous variable.)

Table 3

Summary of fixed effects in the mixed linear model for the production latencies in Experiment 1.

\begin{tabular}{|c|c|c|c|c|c|}
\hline Predictor & Coefficient & $S E$ & $d f$ & $t$-value & $\operatorname{Pr}(>|t|)$ \\
\hline \multicolumn{6}{|l|}{$\begin{array}{l}\text { Model for all target responses. } \\
\quad \text { Note: } N=2924, \log \text {-likelihood }=-20592.26\end{array}$} \\
\hline Intercept & 1057.89 & 34.98 & 2501 & 30.25 & $<.001^{* * *}$ \\
\hline Target structure & -40.66 & 10.34 & 370 & -3.93 & $<.001^{* * *}$ \\
\hline Cumulative Passive Proportion & -256.18 & 122.50 & 370 & -2.09 & $<.037^{*}$ \\
\hline Syntactic repetition & 21.15 & 8.33 & 370 & 2.54 & $<.012^{*}$ \\
\hline 1 vs. 3 Primes & -6.06 & 5.63 & 370 & -1.08 & $>.2$ \\
\hline Target structure by Cumulative Passive Proportion & 215.42 & 103.30 & 370 & 2.09 & $<.038^{*}$ \\
\hline Syntactic Repetition by Target Structure & -5.45 & 8.40 & 370 & -0.65 & $>.5$ \\
\hline Syntactic repetition by 1 vs. 3 Primes & -8.83 & 5.08 & 370 & -1.74 & $<.083$ \\
\hline Syntactic Repetition by Cumulative Passive Proportion & -106.46 & 59.30 & 370 & -1.80 & $<.073$ \\
\hline \multicolumn{6}{|l|}{$\begin{array}{l}\text { Model for target responses with active sentence structure. } \\
\text { Note: } N=2538, \log \text {-likelihood }=-17881.13\end{array}$} \\
\hline Intercept & 1018.04 & 35.62 & 2205 & 28.58 & $<.001^{* * *}$ \\
\hline Syntactic Repetition & 16.33 & 5.41 & 283 & 3.02 & $<.003^{* *}$ \\
\hline Cumulative Passive Proportion & -66.27 & 100.00 & 283 & -0.66 & $>.5$ \\
\hline 1 vs. 3 Primes & -7.31 & 5.42 & 283 & -1.35 & $>.18$ \\
\hline Syntactic repetition by 1 vs. 3 Primes & -7.77 & 5.41 & 283 & -1.44 & $>.15$ \\
\hline Syntactic Repetition by Cumulative Passive Proportion & -106.23 & 62.25 & 283 & -1.71 & $<.089$ \\
\hline \multicolumn{6}{|l|}{$\begin{array}{l}\text { Model for target responses with passive sentence structure. } \\
\text { Note: } N=386 \text {, log-likelihood }=-2725.61\end{array}$} \\
\hline Intercept & 1090.38 & 42.40 & 320 & 25.72 & $<.001^{* * *}$ \\
\hline Syntactic Repetition & 17.91 & 16.16 & 16 & 1.11 & $>.3$ \\
\hline Cumulative Passive Proportion & -290.97 & 293.08 & 16 & -0.99 & $>.3$ \\
\hline 1 vs. 3 Primes & 1.08 & 15.85 & 16 & 0.07 & $>.9$ \\
\hline Syntactic repetition by 1 vs. 3 Primes & -14.61 & 15.79 & 16 & -0.93 & $>.3$ \\
\hline Syntactic Repetition by Cumulative Passive Proportion & -113.37 & 210.86 & 16 & -0.54 & $>.5$ \\
\hline
\end{tabular}

${ }^{* * *}<.001 ;{ }^{* *}<.01 ;{ }^{*}<.05 ; \cdot<.1$.

coding (each level of a variable is compared to the grand mean) for categorical variables; continuous variables were centered on the mean.

Fig. 5 and Table 3 summarize the production latency data. In the model summarizing active and passive target response together, we included the random intercept and slope of 'Target Structure' and '1 vs. 3 Primes' for subjects, and the random intercept and slope of 'Target Structure' for items (this is the maximal random effect structure for which convergence is reached). There was a main effect of Target Structure $(p<.001)$, Cumulative Passive Proportion $(p<.037)$ and Syntactic Repetition $(p<.012)$, indicating that production latencies are faster for active structures, faster when the cumulative proportion of passives is higher and faster when structures are primed. There was an interaction between Target Structure and Cumulative Passive Proportion $(p<.038)$ indicating that the production latency difference between actives and passives becomes smaller as the cumulative proportion of passives increases. This points to a cumulative priming 
effect on the production latencies. Also the interaction between Syntactic Repetition and 1 vs. 3 Primes $(p<.083)$ as well as the interaction between Syntactic Repetition and Cumulative Passive Proportion $(p<.07)$ approached significance, suggesting that the effect of repeating the syntactic structure on the latencies is larger when there are 3 primes vs. 1 prime, and increases the more Cumulative Passive Proportion increases. This model fits the data better than a more complex model with a three-way interaction Syntactic Repetition $\times$ Target Structure $\times$ Cumulative Passive Proportion $\left(\chi_{1}^{2}=0.002, p>.9\right)$ or any other more complex model including additional two- or three-way interactions.

To understand the complex pattern of interactions in the results further, we split the data according to the target structure produced. We estimated two separate models, one predicting latencies for active targets and one for passive targets. Each model included all the fixed effects which were included in the model for active and passive target responses together, naturally with the exception of the main effect and interactions including Target Structure. Syntactic repetition significantly speeded up latencies for active structure choices $(p<.003)$ and the interaction effect with Cumulative Passive Proportion approached significance $(p<.089)$ : the higher the cumulative proportion of passives (and thus: the smaller the cumulative proportion of actives), the smaller the priming effect for actives. This indicates there is a cumulative effect of priming for actives in the production latencies. Latencies for passives were unaffected by priming $(p>.3)$, in line with the positive preference effect on latencies previously reported in the literature. In this experiment, cumulativity did not help in bringing about a latency benefit of passive priming.

\section{Experiment 2: The influence of structure preference, verb repetition and cumulativity on the effects of priming on syntactic choices and production latencies}

In the second experiment we again investigated the structural priming effects for actives as well as passives, and thus manipulated structure preference. We also investigated whether the structural priming effects on syntactic choices and latencies are boosted by verb repetition. We again measured the cumulative effect of preceding target productions over the duration of the experiment (i.e. the proportion of passives out of the total active and passive response productions in the experiment so far, or the Cumulative Passive Proportion - see Experiment 1).

\section{Materials and methods of Experiment 2}

\section{Participants}

Forty-five native Dutch speakers (20 male/25 female, mean age of 22 years with $S D$ 3.4) gave written informed consent prior to the experiment and were compensated for their participation.

\section{Materials}

The materials for Experiment 2 were identical to the materials of Experiment 1.

\section{Task and design}

The task of Experiment 2 was identical to the task of Experiment 1: participants were instructed to describe pictures with one sentence, naming the green actor before the red actor if two actors were depicted in color. If the actors were not depicted in color then participants did not have to pay attention to the order and could therefore produce either an active or a passive sentence.

The design of the experiment is illustrated in Fig. 6 . There were two types of prime sentences: (a) baseline prime sentences and (b) transitive prime sentences. Baseline trials, during with an intransitive or locative prime sentence was followed by a transitive target sentence, allowed us to measure the baseline frequency of producing active and passive transitives when not primed by a transitive sentence. There were four transitive priming conditions, resulting from a manipulation of the syntactic structure of the prime (active versus passive), fully crossed with a manipulation verb repetition (no verb repetition versus verb repetition between prime and target). The actors in prime and target pictures were always different (i.e. children followed by adults or vice versa) so participants were never repeating actors names between primes and targets.

Each experimental list contained 48 baseline trials and 24 trials in each of the 4 transitive priming conditions. We randomly choose, from the picture set described above, the target pictures to appear in the 'no verb repetition' and the target pictures to appear in the 'verb repetition' condition; from this we generated 3 counterbalanced lists so that across each triplet of experimental lists the same target picture occurred once with a baseline prime, once with a transitive prime in the active version and once with the same transitive prime but in the passive version (and we repeated this procedure starting from a different random picture subset 15 times, in order to create 45 experimental lists). Within each experimental list, this resulted in 144 transitive descriptions on target pictures, 96 transitive descriptions on prime pictures and 48 intransitive or locative descriptions leading up to a target in the baseline condition. Again intransitive and locative sentences also served as filler sentences (another 192 sentences added). In total there were thus 480 sentences in the experiment. Over the whole experimental list only $50 \%$ of the items (240 out of the total of 480 sentences) elicited transitive sentences.

\section{Experimental procedure and scoring criteria}

The experimental procedure and coding criteria of Experiment 2 were identical to those of Experiment 1.

\section{Data analysis procedure}

Data analysis procedure was identical to Experiment 1.

\section{Results of Experiment 2}

\section{Syntactic choices}

We excluded 6\% (413 out of 6480) of the responses on baseline and transitive priming trials (criteria are described under 'Experimental procedure and scoring criteria'). Fig. 7 and Table 4 summarize the syntactic 
1a Baseline prime sentence

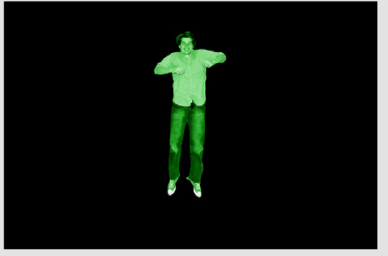

The man jumps

1b Transitive prime sentence

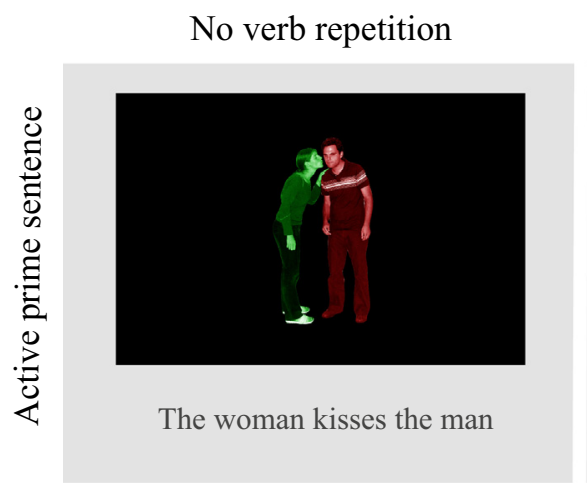

Verb repetition

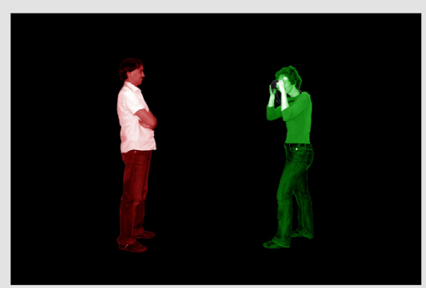

The woman photographs the man
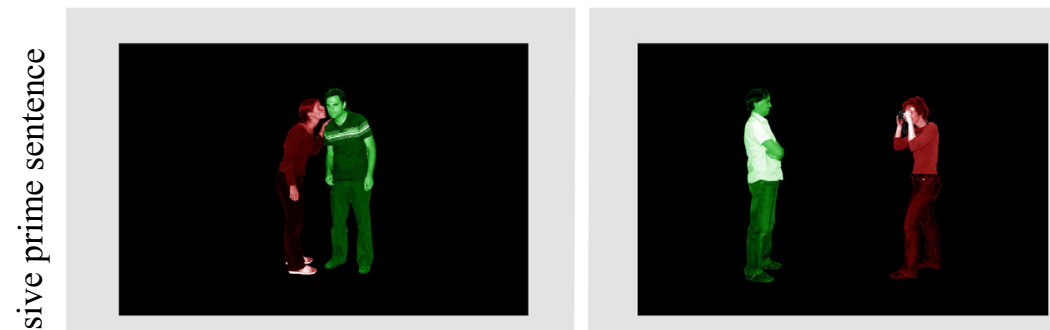

The man is kissed by the woman

The man is photographed by the woman

\section{Target sentence}

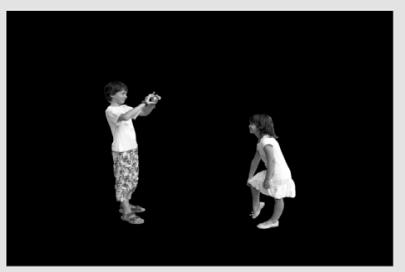

The boy photographs the girl, or:

The girl is photographed by the boy

Fig. 6. Design Experiment 2. Baseline prime sentences (1a) were elicited by pictures in which the actors were colored or grayscale, eliciting an intransitive or locative sentence. Transitive prime sentences (1b) were elicited by pictures in which actors were color-coded for the order of precedence in the sentence, thus eliciting a sentence in active or passive voice. Target sentences (1c) were elicited by grayscale pictures such that we could measure syntactic choice as well as the production latency. We measured structure priming effects in the baseline condition and four transitive priming conditions, the latter resulting from a manipulation of the structure of the prime sentence (active versus passive voice) fully crossed with a manipulation of verb repetition (no verb repetition versus verb repetition). (For interpretation of the references to color in this figure legend, the reader is referred to the web version of this article.) 

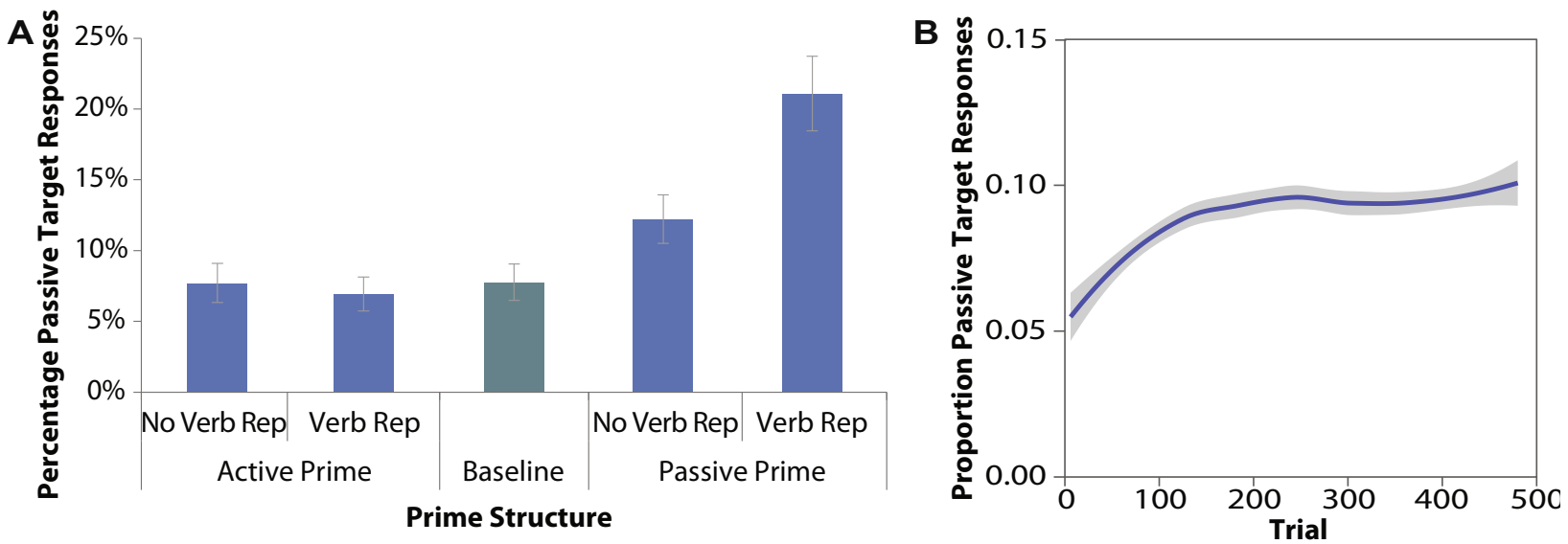

Fig. 7. Syntactic choice results of Experiment 2. (A) Replicating the inverse preference effect, we found that choices were not affected by active primes, but were affected by passive primes compared to baseline. The structural persistence effect is sensitive to verb repetition: choices were influence more by structural priming when the verb between prime and target was also repeated than when it was not repeated. (B) The proportion of passive target responses is illustrated to increase over trials within the experiment. The higher the Cumulative Passive Proportion, the more passives were produced during the target sentence, suggesting cumulativity.

Table 4

Summary of fixed effects in the mixed logit model for the syntactic choices in Experiment 2.

\begin{tabular}{|c|c|c|c|c|}
\hline Predictor & Coefficient & $S E$ & Wald Z & $p$ \\
\hline Intercept (Baseline) & -3.22 & 0.18 & -18.35 & $<.001^{* * *}$ \\
\hline Active Prime - No Verb Repetition & -0.12 & 0.17 & -0.73 & $>.47$ \\
\hline Active Prime - Verb Repetition & -0.27 & 0.17 & -1.58 & $>.12$ \\
\hline Passive Prime - No Verb Repetition & 0.71 & 0.15 & 4.83 & $<.001^{* * *}$ \\
\hline Passive Prime - Verb Repetition & 1.37 & 0.17 & 7.94 & $<.001^{* * *}$ \\
\hline Cumulative Passive Proportion & 5.03 & 0.78 & 6.48 & $<.001^{* * *}$ \\
\hline
\end{tabular}

Note: $N=6067$, log-likelihood $=-1707$.

${ }^{* * *}<.001$.

choices data. The random effects structure for the model includes a random intercept for subjects and items and a random slope for Condition (this is the maximal random effect structure for which convergence is reached).

To assess whether the priming effect on syntactic choices is greater for passives than actives (i.e. the inverse preference effect), one must compare syntactic choices in priming conditions to a baseline condition. In order to statistically assess these crucial comparisons, a predictor 'Condition' with five levels was added to the model, such that the baseline condition was included in the intercept and contrasted with the four conditions that result from fully crossing 'Prime structure' and 'Verb Repetition'. Also, like in Experiment 1, a predictor 'Cumulative Passive Proportion' (i.e. the proportion of passives out of the total active and passive response productions in the experiment so far) centered on the mean was included to assess cumulativity.

Target responses were coded as 0 for actives and 1 for passives. The negative estimate for the intercept thus indicates that in the baseline condition actives were more frequent than passives. Again replicating the inverse preference effect, we found that syntactic choices were not affected by active primes compared to baseline (novel verb: $p>.4$, repeated verb: $p>.1$ ), but were affected by passive primes compared to baseline (novel verb: $p<.001$, repeated verb: $p<.001)$. The structural persistence effect was sensitive to verb repetition: more passives were produced following a passive prime with the same verb than a different verb $(\beta=.67, p<.001)$. Similar to Experiment 1, the higher the Cumulative Passive Proportion within the experiment so far, the more passives were produced during the target sentence $(p<.001)$, thus replicating the finding of cumulativity. Not surprisingly, there were not more active productions following verb repetition than no verb repetition $(\beta=-0.14, p>.48)$. A model including an interaction between Cumulative Passive Proportion and Condition was not a better model fit than a model excluding this interaction $\left(\chi_{4}^{2}=5.25, p>.26\right)$.

\section{Production latencies}

Identical to the analyses of the production latencies of Experiment 1, we created a post hoc variable "Syntactic repetition" with the levels No syntactic repetition and Syntactic repetition. This variable captures the relationship between the prime structure and the structure of the participant's target response. In other words, when this variable shows to be a significant predictor of the latencies, it demonstrates that there is a relationship between the structural persistence effect and the priming effect on the latencies. 
A

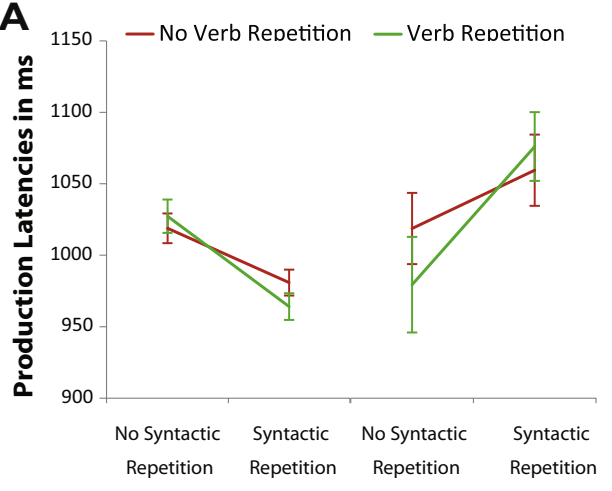

Actives
B

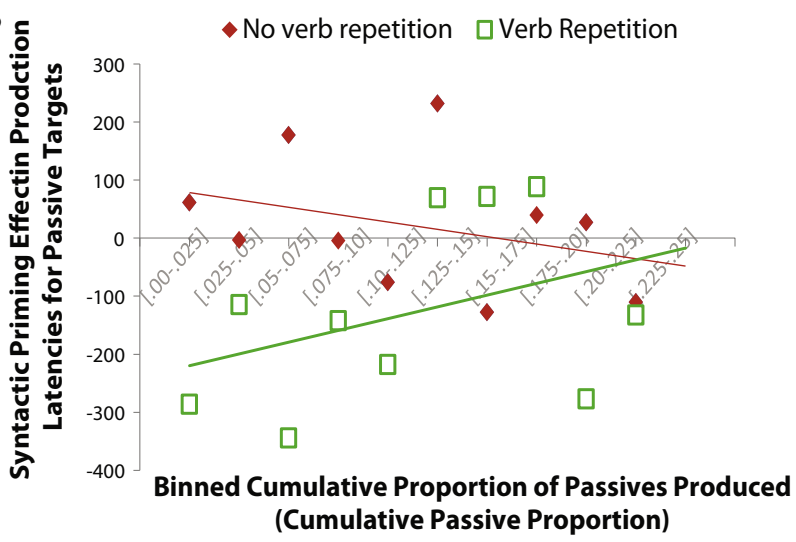

Fig. 8. Production latency results of Experiment 2. (A) The syntactic repetition effects are plotted for the Verb Repetition and No Verb Repetition condition separately. Syntactic repetition significantly speeded up latencies for active structure choices, but not for passive structure choices, in line with the positive preference in latencies previously reported in the literature. (B) The syntactic repetition effect for passives interacted with Cumulative Passive Proportion and Verb Repetition in the three-way interaction: priming for passives correlates positively with the Cumulative Passive Proportion value but only when also aided by verb repetition. In other words, the higher the Cumulative Passive Proportion, the larger the passive priming effect, but only when the verb between prime and target was repeated. (Cumulative Passive Proportion is binned for visualization purposes. Analyses are done with Cumulative Passive Proportion as a continuous variable.)

Table 5

Summary of fixed effects in the mixed linear model for the production latencies in Experiment 2.

\begin{tabular}{|c|c|c|c|c|c|}
\hline Predictor & Coefficient & $S E$ & $d f$ & $t$-value & $\operatorname{Pr}(>|t|)$ \\
\hline \multicolumn{6}{|l|}{ Model for all target responses. } \\
\hline Intercept & 1048.68 & 30.92 & 3090 & 33.92 & $<.001^{* * *}$ \\
\hline Target Structure & -55.63 & 12.64 & 494 & -4.40 & $<.001^{* * *}$ \\
\hline Syntactic Repetition & 11.74 & 8.06 & 494 & 1.46 & $>.14$ \\
\hline Verb Repetition & 1.85 & 8.01 & 494 & 0.23 & $>.8$ \\
\hline Cumulative Passive Proportion & 5.85 & 107.73 & 494 & 0.06 & $>.9$ \\
\hline Target Structure by Syntactic Repetition & 15.18 & 8.04 & 494 & 1.89 & $<.06$ \\
\hline Target Structure by Verb Repetition & 1.48 & 8.02 & 494 & 0.18 & $>.8$ \\
\hline Syntactic repetition by Verb Repetition & 2.85 & 8.00 & 494 & 0.39 & $>.7$ \\
\hline Target Structure by Cumulative Passive Proportion & 82.63 & 88.76 & 494 & 0.93 & $>.3$ \\
\hline Verb Repetition by Cumulative Passive Proportion & 57.18 & 72.09 & 494 & 0.79 & $>.4$ \\
\hline Verb Repetition by Cumulative Passive Proportion & 22.25 & 72.12 & 494 & 0.31 & $>.7$ \\
\hline Target Response by Verb Repetition by Syntactic Repetition & -8.19 & 8.00 & 494 & -1.02 & $>.3$ \\
\hline Target Response by Verb Repetition by Cumulative Passive Proportion & 8.66 & 72.22 & 494 & 0.12 & $>.9$ \\
\hline Target Structure by Verb Repetition by Cumulative Passive Proportion & 8.48 & 72.17 & 494 & .012 & $>.9$ \\
\hline Syntactic Repetition by Verb Repetition by Cumulative Passive Proportion & -140.03 & 71.95 & 494 & -1.95 & $<.052$ \\
\hline Target structure by Syntactic Repetition by Verb Repetition by Cumulative Passive Proportion & 124.55 & 72.03 & 494 & 1.73 & $<.084$ \\
\hline \multicolumn{6}{|l|}{$\begin{array}{l}\text { Model for target responses with active sentence structure. } \\
\text { Note: } N=3225 \text {, log-likelihood }=-22261.54\end{array}$} \\
\hline Intercept & 992.77 & 23.93 & 2761 & 41.49 & $<.001^{* * *}$ \\
\hline Syntactic Repetition & 26.55 & 4.21 & 412 & 6.31 & $<.001^{* * *}$ \\
\hline Verb Repetition & 2.78 & 5.86 & 412 & 0.48 & $>.6$ \\
\hline Cumulative Passive Proportion & 44.18 & 93.95 & 412 & 0.47 & $>.6$ \\
\hline Syntactic repetition by Verb Repetition & -5.59 & 4.21 & 412 & -1.33 & $>.18$ \\
\hline Syntactic Repetition by Cumulative Passive Proportion & 61.87 & 52.75 & 412 & 1.17 & $>.2$ \\
\hline Verb Repetition by Cumulative Passive Proportion & 50.14 & 64.46 & 412 & 0.78 & $>.4$ \\
\hline Syntactic Repetition by Verb Repetition by Cumulative Passive Proportion & -7.14 & 52.78 & 412 & -0.14 & $>.8$ \\
\hline \multicolumn{6}{|l|}{$\begin{array}{l}\text { Model for target responses with passive sentence structure. } \\
\text { Note: } N=419, \log \text {-likelihood }=-2883.27\end{array}$} \\
\hline Intercept & 1104.14 & 43.09 & 355 & 25.63 & $<.001^{* * *}$ \\
\hline Syntactic Repetition & -0.98 & 13.26 & 16 & -0.07 & $>.9$ \\
\hline Verb Repetition & 0.88 & 17.67 & 16 & 0.05 & $>.9$ \\
\hline Cumulative Passive Proportion & -145.40 & 195.42 & 16 & -0.74 & $>.4$ \\
\hline Syntactic repetition by Verb Repetition & 0.95 & 13.20 & 16 & 0.07 & $>.9$ \\
\hline Syntactic Repetition by Cumulative Passive Proportion & -7.88 & 137.38 & 16 & -0.06 & $>.9$ \\
\hline Verb Repetition by Cumulative Passive Proportion & -23.88 & 159.90 & 16 & -0.15 & $>.8$ \\
\hline Syntactic Repetition by Verb Repetition by Cumulative Passive Proportion & -303.40 & 137.06 & 16 & -2.21 & $<.05^{*}$ \\
\hline
\end{tabular}

${ }^{* * *}<.001 ;{ }^{*}<.05 ; \cdot<.1$. 
Of the correct responses on the priming trials, we excluded 9\% (340 out of 3984) because they contained sounds triggering the voice key before speech onset or because they were two standard deviations below or above the mean calculated per subject and per condition (Ratcliff, 1993). We used deviation coding (each level of a variable is compared to the grand mean) for categorical variables; continuous variables were centered on the mean.

Fig. 8 and Table 5 summarize the production latency data. For the model predicting active and passive targets together, we included the random intercept and slope of 'Target Structure' for subjects as well as items (this is the maximal random effect structure for which convergence is reached). There was a main effect of Target Structure $(p<.001)$ indicating that latencies are faster for active structures. There were also three interactions which approached significance: Target Structure by Syntactic Repetition $(p<.06)$, Syntactic Repetition by Verb Repetition by Cumulative Passive Proportion $(p<.052)$, Target structure by Syntactic Repetition by Verb Repetition by Cumulative Passive Proportion $(p<.084)$. A model including the latter 4-way interaction was significantly a better fit for the data than a model without the 4-way interaction $\left(\chi_{1}^{2}=4.25, p>.039\right)$.

To understand this complex pattern of interactions in the results, we split the data according the target structure produced. We estimated two separate models, one predicting latencies for active targets and one for passive targets. Each model included all the fixed effects which were included in the model for all target responses together, naturally with the exception of the main effect or interactions including Target Structure. The model for active targets had a random intercept and a random slope for Verb Repetition for subjects as well as items. The model for passive targets had a random intercept for subjects and items but only a random slope for Verb Repetition for subjects.

The results of these models revealed that syntactic repetition significantly speeds up latencies for active structure choices $(p<.001)$. Cumulative Passive Proportion did not affect the latency benefit of repeating actives (unlike Experiment 1). For passive structure choices, there was a 3 -way interaction Syntactic repetition $\times$ Verb repetition $\times$ Cumulative Passive Proportion $(p<.05)$ : in the latencies, priming for passives correlates positively with the Cumulative Passive Proportion value, but only when also aided by verb repetition. This suggests that priming in latencies is sensitive to cumulativity as well as verb repetition. Only when priming is boosted by verb repetition, latencies for passives can benefit from repetition as the Cumulative Passive Proportion increases.

\section{Discussion}

Theoretical arguments which are made based on structural priming findings, center around the architectures and mechanisms of the system responsible for language processing and syntactic encoding, e.g. the relationship between lexical and syntactic information, how syntactic structures are learned. Structural priming experiments focusing on syntactic choices have been highly informative. The question we have addressed here is whether structural priming effects on production latencies are driven by common mechanisms and can be explained by an integrated model.

Our experiments yielded several consistent patterns of results. There were significant effects in both choice and latencies data of the three factors we aimed to test. With regard to structure preference and verb repetition our findings are in accordance with predictions of the Two-stage Competition model. With regard to cumulativity our findings partially fit the predictions (see overview of the findings in Table 6). In the Two-stage Competition model, outlined in the introduction, there is a selection stage, during which the speaker selects a mapping from the message onto one structural alternative (e.g. an active or passive), and a planning stage during which the global structure of the hierarchical syntactic frame is assembled, and the local structure of the initial phrase is planned prior to output. While structure choice is determined exclusively during the selection stage, production latency is an additive effect of the time taken in both the selection and planning stages. The Two-stage Competition model is an integrated model designed to explain the discrepancy in effects of structure preference on structural priming observed in choice versus latency data.

According to the Two-stage Competition model, the base-level activations of mutually inhibitory structural alternatives are determined by the corresponding structure preference and established through implicit learning. The inverse preference effect on choice is then due to more activation needing to be sent to activate the less preferred structure on the prime sentences and thus more residual activation being present for the less preferred structural alternative during production of subsequent target sentences. In contrast latencies are a function of both the time needed to select a structure choice (i.e. selection time), and the time required to plan the structure for output (i.e. planning time). While the planning time always decreases as a result of priming, the time needed to select a structure choice is determined by the time needed to solve competition between competing syntactic alternatives. For preferred structures, solving competition is less timeconsuming and priming will even further decrease the selection time: the difference in activation level between the preferred structure and its competitor increases during the target sentence due to residual activation so less time is needed to resolve competition. But for less preferred structures, priming decreases the difference in activation levels between competitors compared to the base-level situation due to residual activation, thus priming increases the time needed to resolve competition, therefore likely eliminating any facilitatory effect of priming on the latency for less preferred structures. Of course, in some cases, even less preferred structures can show a latency benefit due to priming: as long as the amount to which planning is speeded due to structural priming, is greater than the time required to resolve competition at the selection stage, facilitatory effects of priming can be observed on sentence production latencies. 
Table

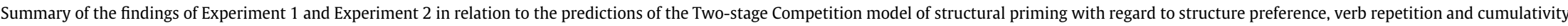

\begin{tabular}{|c|c|c|c|c|c|}
\hline & & Structure preference & Verb repetition & Cumulativity & \\
\hline \multirow[t]{4}{*}{ Structural Choice } & Prediction & $\begin{array}{l}\text { More structural } \\
\text { persistence for the less } \\
\text { preferred structure }\end{array}$ & $\begin{array}{l}\text { More structural persistence when the } \\
\text { verb is repeated }\end{array}$ & Cumulativity increases structural persistence & \\
\hline & Confirmed? & Yes & Yes & Yes & \\
\hline & $\begin{array}{l}\text { Results } \\
\text { Experiment } 1\end{array}$ & $\begin{array}{l}\text { Structural persistence for } \\
\text { passives. } \\
\text { No structural persistence } \\
\text { for actives }\end{array}$ & n.a. & $\begin{array}{l}\text { Short term: There is structural persistence for } \\
\text { passives following } 1 \text { prime, and the persistence } \\
\text { effect is larger following } 3 \text { primes }\end{array}$ & $\begin{array}{l}\text { Long term: The more passive targets } \\
\text { produced in the experiment so far, the } \\
\text { higher the likelihood of producing another } \\
\text { passive }\end{array}$ \\
\hline & $\begin{array}{l}\text { Results } \\
\text { Experiment } 2\end{array}$ & $\begin{array}{l}\text { Structural persistence for } \\
\text { passives. } \\
\text { No structural persistence } \\
\text { for actives }\end{array}$ & $\begin{array}{l}\text { There is structural persistence for } \\
\text { passives when the verb is not } \\
\text { repeated, and the persistence effect is } \\
\text { larger when the verb is repeated }\end{array}$ & Short term: n.a. & $\begin{array}{l}\text { Long term: The more passive targets } \\
\text { produced in the experiment so far, the } \\
\text { higher the likelihood of producing another } \\
\text { passive }\end{array}$ \\
\hline \multirow[t]{4}{*}{$\begin{array}{l}\text { Production } \\
\quad \text { Latencies }\end{array}$} & Prediction & $\begin{array}{l}\text { Larger latency benefit of } \\
\text { repeating the more } \\
\text { preferred structure }\end{array}$ & $\begin{array}{l}\text { Latency benefit increases when there } \\
\text { is verb repetition }\end{array}$ & Latency benefit increases with cumulativity & \\
\hline & Confirmed? & Yes & Yes & Partially & \\
\hline & $\begin{array}{l}\text { Results } \\
\text { Experiment } 1\end{array}$ & $\begin{array}{l}\text { There is a latency benefit } \\
\text { of repeating actives but } \\
\text { not passives }\end{array}$ & n.a. & $\begin{array}{l}\text { Short term: No. Syntactic repetition effect is } \\
\text { stronger following } 3 \text { primes, but the effect is } \\
\text { weak and does not hold in simple comparisons } \\
\text { for actives and passives separately }\end{array}$ & $\begin{array}{l}\text { Long term: Yes, weak effect for actives. } \\
\text { Syntactic repetition effect for actives is } \\
\text { stronger the less passives have been } \\
\text { produced in the experiment so far. } \\
\text { No effect for passives }\end{array}$ \\
\hline & $\begin{array}{l}\text { Results } \\
\text { Experiment } 2\end{array}$ & $\begin{array}{l}\text { There is a latency benefit } \\
\text { of repeating actives but } \\
\text { not passives }\end{array}$ & $\begin{array}{l}\text { For passives, verb repetition increases } \\
\text { latency benefits when passive target } \\
\text { production has accumulated. } \\
\text { There is no effect for actives because } \\
\text { there is a ceiling effect in selecting } \\
\text { actives }\end{array}$ & Short term: n.a. & $\begin{array}{l}\text { Long term: Yes, for passives when there is } \\
\text { verb repetition. } \\
\text { Syntactic repetition effect for passives } \\
\text { with repeated verbs is stronger the more } \\
\text { passives have been produced in the } \\
\text { experiment so far. } \\
\text { Contrary to predictions, there is no effect } \\
\text { for actives }\end{array}$ \\
\hline
\end{tabular}


Although the Two-stage Competition model was designed with the main purpose to explain the dissociating effects of structure preference on choices and latencies, predictions can be derived for two other factors that are attested to influence priming in choice data. Whether or not factors that affect structure choices are observed in latencies, will be a function of whether these factors affect the selection time and/or the planning time. As we discussed in the introduction, verb repetition is not expected to influence the planning stage but will impact only on the processes taking place in the selection stage of the Twostage Competition model. Verb repetition can magnify the effect of priming on the selection time (and thus, the resulting overall production latency) since nodes representing syntactic alternatives are linked to specific verbs and additional residual activation is present during target processing when there is verb repetition. Latency benefits are also predicted to increase with cumulativity, due to changes in both the selection and the planning stage. Cumulative priming results in changed base-level activations, which in turn affects competition between syntactic alternatives and the selection time; cumulativity is also expected to affect the planning time.

We will now discuss our findings in more detail. Firstly, we replicated the inverse preference effect for priming on choices in Experiment 1 as well as Experiment 2: there were structural persistence effects for passives and not for actives (Bernolet et al., 2009; Bock, 1986; Bock \& Loebell, 1990; Hartsuiker \& Kolk, 1998). In addition we replicated the positive preference effect for priming on latencies in Experiment 1 and Experiment 2: overall latencies showed priming for actives but not for passives (Segaert et al., 2011, 2014). This pattern of results can be explained by the Two-stage Competition model. Priming an active structure will have little effect on the structure selection stage due to extreme asymmetry in preference. In contrast priming a passive structure has a large effect on the structure selection likelihood. However the increase in activation level of the passive structure is not large enough to surpass that of the active structure, therefore the passive is still slow to be selected as the structure choice outcome. And as long as the amount to which planning is speeded due to structural priming, is not greater than the time required to resolve competition at the selection stage, no facilitatory effect of priming will be observed on sentence production latencies.

Note that actives and passives have a very strong asymmetry with regard to structure preference. There is a clear ceiling effect in selecting actives, therefore actives are not expected to show a structural persistence effect and, on the other side of the coin, passives are unlikely to show a latency benefit due to structural repetition. The Twostage Competition model predicts more structural persistence for the less preferred structure and stronger latency benefits due to structural repetition for the more preferred structure, as a matter of degree and thus not as a matter of all or nothing. For preferred structures with a less asymmetrical relationship with their alternative, the model predicts structural persistence effects and this has been confirmed in experiments on the dative alternation (e.g. Segaert et al., 2014). Likewise, for less preferred structures with a less asymmetrical relationship with their alternative, the model predicts priming effects on production latencies and this has been confirmed in experiments on the dative alternation (e.g. Segaert et al., 2014). As we argued in the introduction, the consistently diverging effect pattern for structural preference across the two dependent variables has important implications for how one models syntactic encoding.

Another main interest in the present report are the possible modulations of the effects of priming on syntactic choices and production latencies by the factors cumulativity and verb repetition. We will first discuss the influence of cumulativity and verb repetition on structural persistence effects in syntactic choices, before turning to a discussion of the production latencies in the next paragraph. Effects of cumulativity on structural persistence were observed in both experiments. In Experiment 1 we found an immediate effect of cumulativity on structural priming of syntactic choice: there was stronger structural persistence for passives preceded by three compared to one structural prime. In addition, passive choices in both experiments increased as a function of the cumulative effect of all preceding target productions over the duration of the experiment (in line with previous observations, e.g. Jaeger \& Snider, 2013). This indicates there was a long term effect of cumulativity as well. Importantly, actives showed no structural persistence as a result of either short or long term cumulative priming. We interpret this pattern as a ceiling effect in the choices for actives, which might not be observed for structural alternatives with a less extreme preference asymmetry. In support of this view, Segaert et al. demonstrated that structural persistence for actives can be observed following a training manipulation that changes the relative preference bias for actives and passives in a way that decreases the preference for actives (Experiment 2 in Segaert et al., 2014). In Experiment 2 of this report, structure choices were again modulated by long term cumulative production of passives. In Experiment 2, there was also a manipulation of verb repetition. In line with previous literature (e.g. Pickering \& Branigan, 1998), the effect of passive primes on syntactic choices was shown to be boosted by verb repetition.

We will now discuss the influence of cumulativity and verb repetition on the syntactic repetition effects on production latencies. First, we will discuss the effects for actives. In Experiment 1 the effect of cumulativity on latency priming was shown for active sentences but only over the long term, such that active priming showed a weak increase as a function of the cumulative effect of all preceding target productions over the duration of the experiment. No difference in latency priming strength was observed due to one versus three immediately preceding primes. However, in Experiment 2, the modulatory influence of the cumulative effect of preceding target productions on the latency benefit of priming for actives sentences was not replicated. The Two-stage Competition model predicts latency benefits to increase when there is cumulativity due to changes in both the selection and the planning stage. For actives, the influence of cumulativity on the selection stage is unlikely because the selection of actives is already at ceiling (indeed, no effects of 
cumulativity on syntactic choices for actives were observed). But even though cumulativity thus does not impact on the selection time for actives due to the high preference asymmetry, the model also predicts cumulativity to affect planning time and therefore a cumulativity influence on latency benefits of repeating actives is predicted by the model. Our findings only partly confirm this prediction, since the effects are observed in Experiment 1 but not in Experiment 2. At the moment it is unclear why this is what we observed. With respect to the influence of verb repetition on production latencies, our results did confirm predictions of the Two-stage Competition model. The production latency benefit of repeating a syntactic structure is predicted to increase when there is verb repetition due to changes in the selection stage. Verb repetition is not predicted to affect the planning stage. For actives, which have a strongly asymmetrical relationship with their alternative, priming does not cause any further changes in the selection stage due to a ceiling effect (indeed, no effects of verb repetition on syntactic choices for actives were observed) and thus no modulations of the selection time due to verb repetition are observed in the latency measurements for actives.

After discussing the effects for actives, we will now discuss the effects of cumulativity and verb repetition on production latencies of syntactic repetition for passives. The findings for passives are in accordance with the model. The Two-stage Competition model predicts latency benefits to increase when there is cumulativity due to changes in both the selection and the planning stage. For less preferred structures, cumulative exposure can boost the base-level activation of the structure to such a level that when preceded by an immediate prime, the less preferred structure now has an activation level close to or even higher than that of the preferred structure; cumulativity is also expected to affect the planning time. With respect to the influence of verb repetition on latency priming, the model predicts production latency benefits of repeating a syntactic structure to increase when there is verb repetition due to changes in the selection stage: verb repetition magnifies the effect of priming on the selection time, because nodes representing syntactic alternatives are linked to specific verbs. Cumulativity and verb repetition can also jointly increase the latency benefits of repeating syntactic structures. Our results show that in Experiment 1 , cumulativity did not help in bringing about a latency benefit of passive priming. In Experiment 2, cumulativity again did not help in bringing about a latency benefit of passive priming, at least when there was no verb repetition. This suggests that at least without the help of verb repetition the activation level of the passives is not boosted by cumulativity to such an extent that it reaches the same level of activation than the preferred structure. In Experiment 2, there was production latency priming for passives when they were boosted by cumulativity as well as verb repetition. Only with cumulative exposure to passives, did verb repetition result in the primed passive being more activated than the active, therefore resulting in speeded selection times and by consequence also speeded response latencies. The combined effect of cumulative structure priming and verb repetition thus increases the activation level of the passive enough and speeds the competition resolution for passive choice sufficiently for the production latency benefit to be observed.

In summary, the presently observed data pattern is largely in accordance with the Two-stage Competition model. This is an integrated model that provides an explanation for a large amount of observed empirical effects of structural priming on choice and latency measures, including the diverging effect of structure preference on priming of choice versus latency. The model also accounts for another difference that has been reported in the literature. Wheeldon and Smith (2003) demonstrated a structural priming effect on latencies that was short lived, as it failed to survive just one intervening sentence that was unrelated. This is in contrast to the long-lived and cumulative effects observed for priming of syntactic choices. Wheeldon and Smith (2003) also suggested a two-stage explanation for this difference, with choice tapping into the mapping from conceptual to syntactic structure and latency tapping into incremental phrasal planning. Importantly however, Wheeldon and Smith (2003) did not test this claim directly as their paradigm did not require speakers to select between alternative structures, and therefore focused on planning processes only. The Two-stage Competition model makes a similar assumption about the transience of structural priming at the level of planning, but goes one step further in that it makes explicit predictions about the relationship between choice and planning, by specifying the time course of structure selection and its contribution to sentence production latencies as well.

The present study has generated questions for further research however. The Two-stage Competition model predicts that the timing of sentence selection processes is directly related to the relative structural preferences. Further studies using a range of syntactic alternatives are required to test this prediction. Moreover, the Two-stage Competition model assumes the global planning of the hierarchical sentence structure but the detailed local planning of only the initial phrase structure, prior to speech onset. In the present study we have only manipulated and measured effects of priming on the former. Our model thus predicts effects of incremental planning complexity that have not yet been tested in a paradigm including structural choice, as the front end of the active, passive and dative alternatives that have been tested to date (Segaert et al., 2011, 2014), have had the same initial phrase structure. We are currently testing these aspects of the model in ongoing projects.

The aim of this research was to bring together two fields that have developed largely in parallel, namely structural priming research which predominantly uses choice as the dependent variable, and sentence generation research which mainly measures latencies. However when we produce sentences we must select structures as well as plan them for output. Therefore accurate models of how structural choice and planning relate to each other are required and such models must be constrained both by choice and latency data. In this article we have tested such a model and provided new data that further develop our understanding of the relationship between the selection and the generation of sentences during speaking. 


\section{Acknowledgments}

We would like to thank Charlotte Poulisse and Nadine de Rue for much appreciated help with data collection and coding of the responses. We acknowledge, with gratitude, Kathryn Bock's, Gary Dell's and an anonymous reviewer's comments on the manuscript.

\section{Appendix}

See Table 1.

\section{References}

Allum, P. H., \& Wheeldon, L. (2009). Scope of lexical access in spoken sentence production: Implications for the conceptual-syntactic interface. Journal of Experimental Psychology: Learning, Memory, and Cognition, 35(5), 1240-1255. http://dx.doi.org/10.1037/a0016367.

Allum, P. H., \& Wheeldon, L. R. (2007). Planning scope in spoken sentence production: The role of grammatical units. Journal of Experimental Psychology: Learning, Memory, and Cognition, 33(4), 791-810. http:// dx.doi.org/10.1037/0278-7393.33.4.791.

Barr, D. J., Levy, R., Scheepers, C., \& Tily, H. J. (2013). Random effects structure for confirmatory hypothesis testing: Keep it maximal. Journal of Memory and Language, 255-278.

Berg, T., \& Schade, U. (1992). The role of inhibition in a spreadingactivation model of language production. I. The psycholinguistic perspective. Journal of Psycholinguistic Research, 21(6), 405-434.

Bernolet, S., \& Hartsuiker, R. J. (2010). Does verb bias modulate syntactic priming? Cognition, 114(3), 455-461. http://dx.doi.org/10.1016/j. cognition.2009.11.005.

Bernolet, S., Hartsuiker, R. J., \& Pickering, M. J. (2009). Persistence of emphasis in language production: A cross-linguistic approach. Cognition, 112(2), 300-317.

Bock, K. (1986). Syntactic persistence in language production. Cognitive Psychology, 18(3), 355-387.

Bock, K., \& Ferreira, V. S. (2014). Syntactically speaking. In M. Goldrock, V. Ferreira, \& M. Miozzo (Eds.), The Oxford handbook of language production (pp. 21-46). NY: Oxford University Press.

Bock, K., \& Griffin, Z. M. (2000). The persistence of structural priming: Transient activation or implicit learning? Journal of Experimental Psychology: General, 129(2), 177-192. http://dx.doi.org/10.1037// 0096-3445.129.2.177.

Bock, K., \& Levelt, W. J. M. (1994). Language production: Grammatical encoding. In M. A. Gernsbacher (Ed.), Handbook of psycholinguistics (pp. 945-984). London: Academic Press.

Bock, K., \& Loebell, H. (1990). Framing sentences. Cognition, 35, 1-39.

Branigan, H. P., Pickering, M. J., \& Cleland, A. A. (1999). Syntactic priming in written production: Evidence for rapid decay. Psychonomic Bulletin E' Review, 6(4), 635-640.

Branigan, H. P., Pickering, M. J., \& Cleland, A. A. (2000). Syntactic coordination in dialogue. Cognition, 75(2), B13-B25.

Bresnan, J. (2001). Lexical-functional syntax.Cambridge, MA: Blackwell.

Brown-Schmidt, S., \& Konopka, A. E. (2008). Little houses and casas pequenas: Message formulation and syntactic form in unscripted speech with speakers of English and Spanish. Cognition, 109(2), 274-280. http://dx.doi.org/10.1016/j.cognition.2008.07.011.

Brown-Schmidt, S., \& Konopka, A. E. (2015). Processes of incremental message planning during conversation. Psychonomic Bulletin \& Review, 22(3), 833-843. http://dx.doi.org/10.3758/s13423-0140714-2.

Chang, F., Baumann, M., Pappert, S., \& Fitz, H. (2014). Do lemmas speak German? A verb position effect in German structural priming. Cognitive Science.

Chang, F., Dell, G. S., \& Bock, K. (2006). Becoming syntactic. Psychological Review, 113(2), 234-272. http://dx.doi.org/10.1037/0033$295 \times 113.2 .234$.

Chang, F., Dell, G. S., Bock, K., \& Griffin, Z. M. (2000). Structural priming as implicit learning: A comparison of models of sentence production. Journal of Psycholinguistic Research, 29(2), 217-229.

Chang, F., Janciauskas, M., \& Fitz, H. (2012). Language adaptation and learning: Getting explicit about implicit learning. Language and Linguistics Compass, 6(5), 259-278.

Cleland, A. A., \& Pickering, M. J. (2003). The use of lexical and syntactic information in language production: Evidence from the priming of noun-phrase structure. Journal of Memory and Language, 49(2), 214-230. http://dx.doi.org/10.1016/s0749-596x(03)00060-3.

Corley, M., \& Scheepers, C. (2002). Syntactic priming in English sentence production: Categorical and latency evidence from an internet-based study. Psychonomic Bulletin \& Review, 9(1), 126-131.

Cornelis, L. (1996). English and Dutch: The passive difference. Language Sciences, 18(1-2), 247-264.

Dell, G. S. (1986). A spreading-activation theory of retrieval in sentence production. Psychological Review, 93(3), 283-321.

Dell, G. S., Burger, L. K., \& Svec, W. R. (1997). Language production and serial order: A functional analysis and a model. Psychological Review, 104(1), 123-147. http://dx.doi.org/10.1037/0033-295x.104.1.123.

Ferreira, V. S. (2003). The persistence of optional complementizer production: Why saying "that" is not saying "that" at all. Journal of Memory and Language, 48(2), 379-398.

Ferreira, V. S., \& Bock, K. (2006). The functions of structural priming. Language and Cognitive Processes, 21(7-8), 1011-1029. http://dx.doi. org/10.1080/016909600824609.

Ferreira, V. S., \& Slevc, L. R. (2007). Grammatical encoding. In M. Gareth Gaskell (Ed.), The Oxford handbook of psycholinguistics (pp. 453-469). Oxford, England: Oxford University Press.

Gleitman, L. R., January, D., Nappa, R., \& Trueswell, J. C. (2007). On the give and take between event apprehension and utterance formulation. Journal of Memory and Language, 57, 544-569.

Griffin, Z. M., \& Bock, K. (2000). What the eyes say about speaking. Psychological Science, 11(4), 274-279. http://dx.doi.org/10.1111/14679280.00255.

Hagoort, P. (2005). On Broca, brain, and binding: A new framework. Trends in Cognitive Sciences, 9(9), 416-423. http://dx.doi.org/10.1016/ j.tics.2006.07.004.

Hartsuiker, R. J., Bernolet, S., Schoonbaert, S., Speybroeck, S., \& Vanderelst, D. (2008). Syntactic priming persists while the lexical boost decays: Evidence from written and spoken dialogue. Journal of Memory and Language, $\quad 58(2), \quad 214-238 . \quad$ http://dx.doi.org/10.1016/j. jml.2007.07.003.

Hartsuiker, R. J., \& Kolk, H. H. J. (1998). Syntactic persistence in Dutch. Language and Speech, 41, 143-184.

Hartsuiker, R. J., Kolk, H. H. J., \& Huiskamp, P. (1999). Priming word order in sentence production. Quarterly Journal of Experimental Psychology Section A: Human Experimental Psychology, 52(1), 129-147.

Hartsuiker, R. J., \& Westenberg, C. (2000). Word order priming in written and spoken sentence production. Cognition, 75(2), B27-B39. http://dx. doi.org/10.1016/s0010-0277(99)00080-3.

Heyselaar, E., Hagoort, P., \& Segaert, K. (2015). In dialogue with an avatar, language behaviour is identical compared to dialogue with a human partner. Behavior Research Methods. http://dx.doi.org/10.3758/ s13428-015-0688-7. Advance online publication.

Jackendoff, R. (2002). Foundations of language: Brain, meaning, grammar, evolution.Oxford: Oxford University Press.

Jaeger, T. F. (2008). Categorical data analysis: Away from ANOVAs (transformation or not) and towards logit mixed models. Journal of Memory and Language, 59(4), 434-446. http://dx.doi.org/10.1016/j. jml.2007.11.007.

Jaeger, T. F., \& Snider, N. (2007). Implicit learning and syntactic persistence: Surprisal and cumulativity. University of Rochester Working Papers in the Language Sciences, 3(1), 26-44.

Jaeger, T. F., \& Snider, N. (2008). Implicit learning and syntactic persistence: Surprisal and cumulativity. Paper presented at the cognitive science society conference, Washington, DC.

Jaeger, T. F., \& Snider, N. (2013). Alignment as a consequence of expectation adaptation: Syntactic priming is affected by the prime's prediction error given both prior and recent experience. Cognition, 127, 57-83.

Joshi, A. K., \& Schabes, Y. (1997). Tree-adjoining grammars. In G. Rozenberg \& A. Salomaa (Eds.). Handbook of formal languages (Vol. 3, pp. 69-124). Berlin: Springer-Verlag.

Kaschak, M. P. (2007). Long-term structural priming affects subsequent patterns of language production. Memory \& Cognition, 35(5), 925-937.

Kaschak, M. P., \& Borreggine, K. L. (2008). Is long-term structural priming affected by patterns of experience with individual verbs? Journal of Memory and Language, 58(3), 862-878. http://dx.doi.org/10.1016/j. jml.2006.12.002.

Kaschak, M. P., Kutta, T. J., \& Schatschneider, C. (2011). Long-term cumulative structural priming persists for (at least) one week. Memory \& Cognition, 39(3), 381-388.

Kaschak, M. P., Loney, R. A., \& Borreggine, K. L. (2006). Recent experience affects the strength of structural priming. Cognition, 99 (3), B73-B82. 
Kempen, G., \& Hoenkamp, E. (1987). An incremental procedural grammar for sentence formulation. Cognitive Science, 11(2), 201-258. http://dx. doi.org/10.1016/s0364-0213(87)80006-x.

Konopka, A. E. (2012). Planning ahead: How recent experience with structures and words changes the scope of linguistic planning. Journal of Memory and Language, 66(1), 143-162. http://dx.doi.org/10.1016/j. jml.2011.08.003.

Konopka, A. E., \& Kuchinsky, S. E. (2015). How message similarity shapes the timecourse of sentence formulation. Journal of Memory and Language, 84, 1-23. http://dx.doi.org/10.1016/j.jml.2015.04.003.

Konopka, A. E., \& Meyer, A. S. (2014). Priming sentence planning. Cognitive Psychology, 73, 1-40. http://dx.doi.org/10.1016/j.cogpsych.2014.04. 001.

Kuchinsky, S. E., \& Bock, J. K. (2010). From seeing to saying: Perceiving, planning, producing. Paper presented at the CUNY sentence processing conference. New York, NY: New York University.

Kuchinsky, S. E., Bock, K., \& Irwin, D. E. (2011). Reversing the hands of time: Changing the mapping from seeing to saying. Journal of Experimental Psychology: Learning, Memory, and Cognition, 37(3), 748-756. http://dx.doi.org/10.1037/a0022637.

Levelt, W. (1989). Speaking: From intention to articulation.Cambridge, MA: MIT Press.

Levelt, W. (1992). Accessing words in speech production - Stages, processes and representations. Cognition, 42(1-3), 1-22. http://dx. doi.org/10.1016/0010-0277(92)90038-j.

Levelt, W., \& Kelter, S. (1982). Surface form and memory in question answering. Cognitive Psychology, 14(1), 78-106.

Macdonald, M. C., Pearlmutter, N. J., \& Seidenberg, M. S. (1994). Lexical nature of syntactic ambiguity resolution. Psychological Review, 101(4), 676-703. http://dx.doi.org/10.1037/0033-295x.101.4.676.

Martin, R. C., Crowther, J. E., Knight, M., Tamborello, F. P., II, \& Yang, C.-L. (2010). Planning in sentence production: Evidence for the phrase as a default planning scope. Cognition, 116(2), 177-192. http://dx.doi.org/ 10.1016/j.cognition.2010.04.010.

McClelland, J. L., \& Elman, J. L. (1986). The trace model of speechperception. Cognitive Psychology, 18(1), 1-86. http://dx.doi.org/ 10.1016/0010-0285(86)90015-0.

Pickering, M. J., \& Branigan, H. P. (1998). The representation of verbs: Evidence from syntactic priming in language production. Journal of Memory and Language, 39(4), 633-651.

Pinheiro, J. C., \& Bates, D. M. (2000). Mixed-effects models in S and S-PLUS. New York: Springer.
R Development Core Team (2009). R: A language and environment for statistical computing, Vienna, Austria.

Ratcliff, R. (1993). Methods for dealing with reaction-time outliers. Psychological Bulletin, 114(3), 510-532.

Reitter, D., Keller, F., \& Moore, J. D. (2011). A computational cognitive model of syntactic priming. Cognitive Science, 35(4), 587-637. http:// dx.doi.org/10.1111/j.1551-6709.2010.01165.x.

Roelofs, A. (1992). A spreading-activation theory of lemma retrieval in speaking. Cognition, 42(1-3), 107-142. http://dx.doi.org/10.1016/ 0010-0277(92)90041-f.

Scheepers, C. (2003). Syntactic priming of relative clause attachments: Persistence of structural configuration in sentence production. Cognition, 89(3), 179-205. http://dx.doi.org/10.1016/s0010-0277(03)00119-7.

Schriefers, H., Teruel, E., \& Meinshausen, R. M. (1998). Producing simple sentences: Results from picture-word interference experiments. Journal of Memory and Language, 39(4), 609-632. http://dx.doi.org/ 10.1006/jmla.1998.2578.

Segaert, K., Menenti, L., Weber, K., \& Hagoort, P. (2011). A paradox of syntactic priming: Why response tendencies show priming for passives, and response latencies show priming for actives. PLOS ONE, 6(10), e24209. http://dx.doi.org/10.1371/journal.pone.0024209.

Segaert, K., Weber, K., Cladder-Micus, M., \& Hagoort, P. (2014). The influence of verb-bound syntactic preferences on the processing of syntactic structures. Journal of Experimental Psychology: Learning, Memory, and Cognition, 40(5), 1448-1460. http://dx.doi.org/10.1037/a0036796.

Smith, M., \& Wheeldon, L. (1999). High level processing scope in spoken sentence production. Cognition, 73(3), 205-246. http://dx.doi.org/ 10.1016/s0010-0277(99)00053-0.

Smith, M., \& Wheeldon, L. (2001). Syntactic priming in spoken sentence production - An online study. Cognition, 78(2), 123-164.

Vosse, T., \& Kempen, G. (2000). Syntactic structure assembly in human parsing: A computational model based on competitive inhibition and a lexicalist grammar. Cognition, 75(2), 105-143.

Wheeldon, L., Ohlson, N., Ashby, A., \& Gator, S. (2013). Lexical availability and grammatical encoding scope during spoken sentence production. Quarterly Journal of Experimental Psychology, 66(8), 1653-1673. http:// dx.doi.org/10.1080/17470218.2012.754913.

Wheeldon, L., \& Smith, M. (2003). Phrase structure priming: A short-lived effect. Language and Cognitive Processes, 18(4), 431-442. 